\title{
Shifting of research trends in islanding detection method - a comprehensive survey
}

\author{
Soham Dutta ${ }^{1}$, Pradip Kumar Sadhu', M. Jaya Bharata Reddy ${ }^{2 *}$ and Dusmanta Kumar Mohanta ${ }^{3}$
}

\begin{abstract}
The augmentation in electricity demand, power system privatization as well as efficacy of renewable resources has paved the way for power system companies and researchers to exploit the field of grid connected distributed generation (DG) and its issues, islanding being a dominant one. Several research works have been conducted to mitigate the issues of islanding detection (ID). In context of this, the paper gives a comprehensive review of islanding issues, standard test systems, criteria and shifting of research trends in islanding detection methods (IDMs). The significant contributions pertain to categorization of IDMs, evaluation of non-detection zone (NDZ) for each test system, disquisition on evolution and advancement of IDMs and its comparisons based on criteria such as NDZ, run on time, nuisance tripping percentage, applicability in multi DG system and implementation cost to draw out the strength and shortcomings of individual methods that will come to aid to the companies or researchers for establishing the applicability and appropriateness of such method for their concerned domain.
\end{abstract}

Keywords: Review, Distributed generation, Islanding detection, Microgrid

\section{Introduction}

The depletion of conventional fossil fuels at a breakneck pace and upsurge in power demand along with power market deregulation has aided in the technical and commercial development of a new paradigm in the DG all around the globe. DG means interconnection of mini or micro on-site distributed energy resources (DERs) generation with the main grid at distribution voltage stage. DERs primarily incorporate renewable and non-conventional energy resources such as solar photovoltaic (PV), hydro, wind, tidal, fuel cell, etc. [1]. Several energy market liberations and advancement in electronics and communication techniques have facilitated the operation of these geographically dispersed DERs through improved SCADA. These interconnected DERs possess the capability of operating both on-grid as well as off-grid mode.

The classical structure of distribution system was passive in nature i.e. it has always considered power flow from higher voltage level to lower voltage level. Active

\footnotetext{
*Correspondence: jayabharat_res@yahoo.co.in

${ }^{2}$ Department of Electrical and Electronics Engineering, National Institute of

Technology, Tiruchirappalli, Tamilnadu, India

Full list of author information is available at the end of the article
}

distribution network includes addition of DERs that are locally integrated into the low voltage distribution system that alters the network architecture and operation, rendering the classical consideration to be less applicable. The active distribution network differentiates from the passive in terms of bi-directionality of power flow, power electronics converter based generation, high fault level variability, etc. Plethoric DG penetration as well as DER placement has notable impacts on protection, operation, reliability and control of the power system [2]. These issues must be critically dealt with before permitting DG market participation for smooth operation of existing power structure along with some additional benefits like active reserve, interruptible loads, loadfollowing, restoration, etc. [3].

One of the major obstacles in redefining the existing grid structure to a smart grid structure in terms of sensitivity and stability is the concern of islanding [4]. Islanding is defined as the situation in which a fragment of the utility system is powered by one or more DG sources while that particular fragment of the system is isolated electrically from the rest of the utility system as depicted in Fig. 1. 


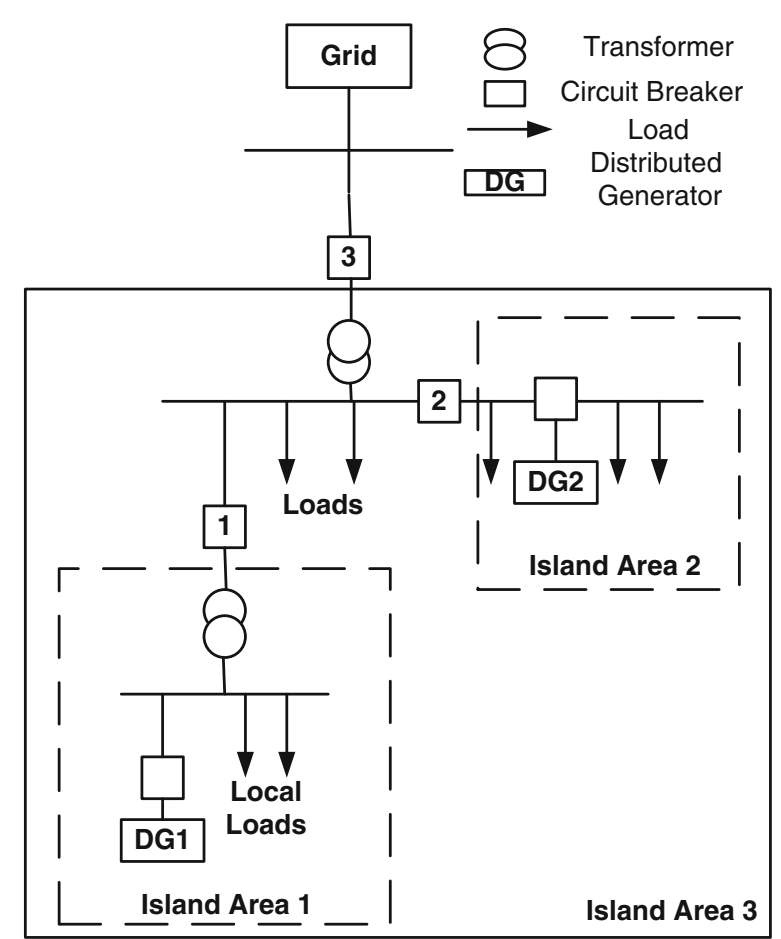

Fig. 1 Concept of islanding

Island area 1, 2 and 3 is formed by opening of circuit breaker 1, 2 and 3 respectively. In light of this, the paper gives a review of IDM available in the research literature to manifest the transition of islanding detection research strategies with time. The methods have been broadly classified into classical and modern methods. A systematic analysis of these techniques is executed to bring to surface the merits and demerits of individual IDM. The rest of the paper is categorized as follows. Section 2 deals with the technical issues and concerns of islanding. The ID standards and criteria of IDM are explored in section 3 and section 4 respectively. Section 5 lays down the underlying theory, working principle and relevant equations of individual IDM. Besides, it also examines and compares various types of IDM. Finally, the work is inferred in section 6 and the future trends are discussed in section 7 .

\section{Technical issues with islanding}

Islanding can be divided into inadvertent or unintentional and deliberate or intentional islanding. Inadvertent islanding is the scenario in which islanding occurs without the prior knowledge of the utility supply or the Independent Power Producer (IPP). The grid disconnection in inadvertent islanding occurs in the following conditions [5]:

- A fault that is detected by the protection mechanism of the grid but not by the protection devices installed in the grid connected DG
- Equipment failure causing accidental disconnection of the normal grid

- Human mistake or malpractices

- An act of nature

In case of unintended islanding, the recent generalized industry standard is disconnection of all the DGs from the islanded portion as quickly as possible [6]. However, some IPP like BC Hydro, Canadian utility have their own requirements to comply with [7]. The undesirable consequences of unintentional islanding are as listed below which illustrates the need of unintentional ID for effective integration of DGs into existing power system topology $[8,9]$ :

- Distributed generations are typically "weak" supplies that are incapable to handle transients efficiently.

- After re-closure of the protective relays, the DGs may not be properly synchronized with that of the main grid resulting in considerable damage to the DGs as well as the utility and consumers.

- If loads do not match to the supply characteristics, then the DG's behavior may be unpredictable.

- Utility workers may be oblivious to the fact that the lines disconnected from the main grid are still energized by the DGs making them prone to health hazards.

- There will be confusion between IPPs and utility for the culpability for degraded power quality.

Intentional islanding is the process of intentionally splitting the grid into separate controllable islands [10]. Deliberate islanding is primarily implemented for averting cascading and blackouts- the two perils to the security of power system. Intentional islanding negates the losses of inadvertent islanding. Intentional islanding may be employed to enhance the voltage profiles and decrease power losses, improve the overall efficiency of the system by controlling the congestion of distribution and transmission system. Therefore, intentional islanding operation can be a viable option if enforced through a proper envelope of research. Various researchers are working on the issues related to intentional islanding in order to eliminate its shortcomings making it practically applicable [11]. Islanding in the correct time and in the correct manner has inspired many works. After proper islanding, the frequency and voltages should be within the prescribed limit to avoid further blackouts [12]. Moreover, intentional islanding will have a significant effect on the electricity prices in the dynamic market [13]. During intentional islanding, several islands will have their own price and the producers can take unconscionable advantage by spiking the prices. Hence these practices should be properly checked. However, they may also give choice to 
customers whether to buy electricity or not under this condition [13].

\section{Test systems, standards and test conditions}

Unfortunately, there is no specific benchmark test system for islanding operation of microgrids. Various countries have installed their own test systems to study about the reliability and feasibility of islanding which are completely distinct from each other. Some of them are based only on one type of DG and some on hybrid generation. IEEE Std. 1547-2003, IEEE Std. 929-2000, Korean Std., VDE 0126-1-1 and UL 1741 are some of the international standards that the IPPs and utility must comply with for effective islanding [14].

Figure 2 shows a generic system for islanding study in accordance with UL 1741 and IEEE 929 as well as IEEE1547. The load inside the potential island (local load) is designed as a parallel RLC circuit as these types of loads pose the greatest difficulty in ID. Specifically, RLC loads possessing a high quality factor are the most problematic element in ID as these have low inductances and high capacitance and/or large resistance. The resonant frequency is considered same as main grid frequency. Mathematically, the load parameters can be stated as in (1)-(4). The RLC load definition is for unity power factor condition. The worst scenario of inadvertent ID occurs when there is no power mismatch between the DG output and load.

$$
\begin{aligned}
& R=V^{2} / P_{L O A D} \\
& L=V^{2} /\left(2 \pi \times f \times Q_{f} \times P_{L O A D}\right)
\end{aligned}
$$

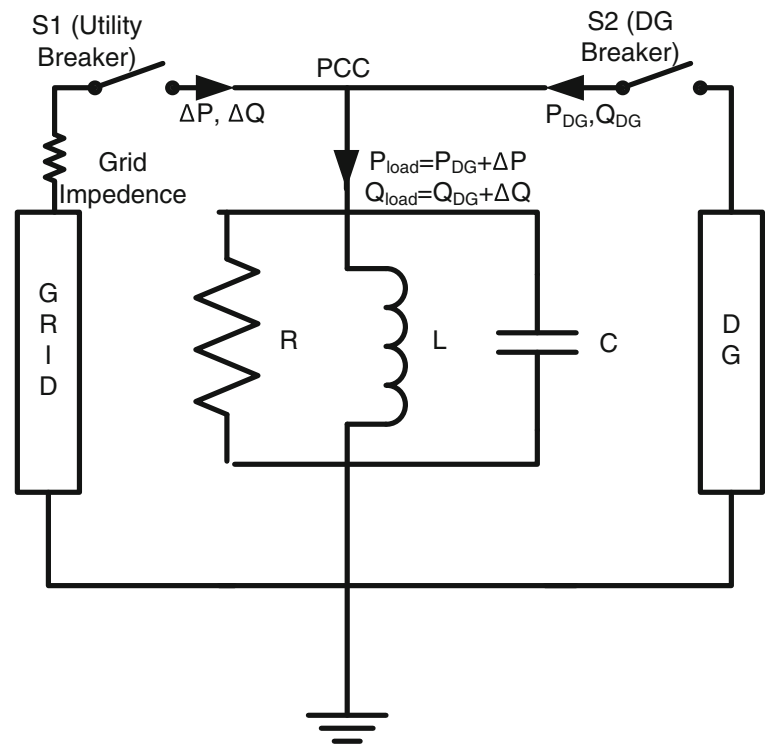

Fig. 2 A generic system for islanding study

$$
\begin{aligned}
& C=Q_{f} \times P_{L O A D} /\left(2 \pi \times f \times V^{2}\right) \\
& f=1 /(2 \pi \times \sqrt{L / C})
\end{aligned}
$$

\section{Criteria for ID methods}

There are a number of criteria that affects the performance of IDM. Unfortunately, there are no techniques currently available which fulfill all the criteria and can be applied for detecting all types of islanding scenarios. These criteria include NDZ, implementation cost, reliability, run on time, effect on power quality, etc.

\subsection{NDZ}

NDZ is the operating region of an IDM in which islanding instances cannot be determined. This is the most significant criteria of an IDM. The performance of an IDM increases with a decrease in NDZ. NDZ can be detected either by load parameter space (LPS) or power mismatch space (PMS) [15].

\subsubsection{LPS}

LPS is appropriate for IDM based on frequency drifting [16]. The phase criteria between the DG output current and the terminal voltage is used to map the NDZ of IDM into LPS or RLC space [17] having axes as L and $\mathrm{C}_{\text {norm }}$ given by (5). This method can predict the NDZ of IDM but not the detection time. Moreover, different curves need to be plotted for analyzing NDZ with different resistive loads. This disadvantage is eliminated in [18] where NDZ is mapped with axes as $\mathrm{Q}_{\mathrm{f}}$ and $\mathrm{f}_{0}$. For a given set of $\mathrm{L}$ and $\mathrm{C}$ loads, an increase in $\mathrm{R}$ automatically means an increase in $\mathrm{Q}_{\mathrm{f}}$.

$$
C_{\text {norm }}=C / C_{\text {res }}=C \times w_{0}^{2} \times L
$$

\subsubsection{PMS}

Under normal condition the voltage and frequency at the point of common coupling (PCC) is governed by the grid condition but under islanded condition it depends on the active and reactive power mismatch between DG production and load consumption. The limits of these power mismatches where the IDM fails to detect islanding is NDZ [19] given by (6)-(7).

$$
\begin{aligned}
& \left(V / V_{\max }\right)^{2}-1 \leq \Delta P / P_{D G} \leq\left(V / V_{\min }\right)^{2}-1 \\
& Q_{f}\left(1-\left(f / f_{\min }\right)^{2}\right) \leq \Delta Q / P_{D G} \leq Q_{f}\left(1-\left(f / f_{\max }\right)^{2}\right)
\end{aligned}
$$

From the above equations, the NDZ is obtained as shown in Fig. 3 [2]. The NDZ for various islanding standards are computed and tabulated in Table 1 where nominal frequency of $50 \mathrm{~Hz}$ is considered. If the active 


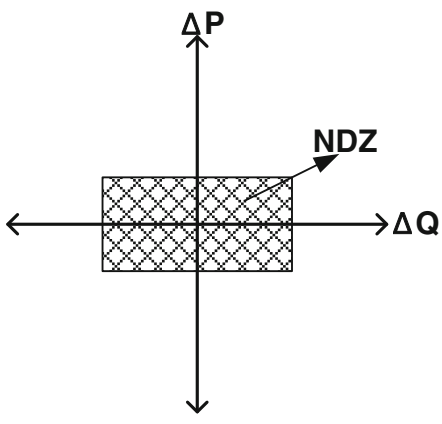

Fig. 3 Schematic diagram of NDZ

and reactive power is within the specified ranges, then the voltage and frequency will remain within nominal range, thus hindering ID.

\subsection{Run on time}

Run on time is the time elapsed from opening of main grid circuit breaker at PCC to the signal send for disconnection of the DGs which is given in (8). A small run on time is preferred so that the DGs can be disconnected quickly causing minimal damage.

$$
T_{r t}=T_{m c b}+T_{c o m}
$$

\subsection{Nuisance tripping percentage}

Though a small NDZ is preferable in IDMs, there should be some allowable margin in order to eliminate nuisance or false tripping. It occurs mainly due to network surge caused by load switching or other disturbances other than grid disconnection [20]. The nuisance tripping percentage can be defined as the percentage of nuisance tripping instants to total detection instants of an IDM and is expressed in (9). The ratio should be as low as possible to avoid unnecessary DG disconnection.

$$
P_{n u i}=\left[I_{n u i}\left(I_{n u i}+I_{i s l}\right)\right] \times 100
$$

\subsection{Effect on microgrid}

IDMs injecting perturbations like harmonics, currents, etc. does not produce any significant effect when the DGs are connected to the main grid but significantly reduces the power quality when in islanded condition. Therefore, IDMs with null or minimal effect on microgrid is preferred.

\subsection{Applicability in multi DG system}

Nowadays, most of the micro-grids are composed of not only more than one DG but several types of DG connected to the same PCC in parallel. The measurement parameters of IDMs may nullify each other owing to each DGs own characteristic variation rendering decreased performance of IDMs. Therefore, the IDMs should possess applicability in multiple DG system. Moreover, with more DG integration in near future, the IDMs should be able to detect intricate islanding.

\subsection{Implementation cost}

Some of the IDMs involve advanced and complicated hardware for successful operation. High performance is obtained at the cost of high investment decreasing its practical application. There should be a compromise between performance and cost for its real time implementation.

\section{IDM}

A plethora of methods is proposed by various researchers for ID. These methods can be broadly classified into classical and modern. The classical system can be further categorized into active, passive, hybrid and local methods while the modern methods can be categorized into signal processing and classifier methods as shown in Fig. 4.

\subsection{Classical}

The classical methods are the edifice of IDMs. These methods analyze the magnitude of a signal directly or indirectly. The number of research papers for each of its subcategories is represented in Fig. 5.

\subsubsection{Passive methods}

These are the first methods to be employed for ID. These methods were introduced around 1990's and became popular around 1995. In these techniques, certain parameters like voltage and frequency at the PCC or at DG terminals are measured to detect islanding. A threshold value is set for these parameters exceeding which indicates islanding. These methods can detect

\begin{tabular}{|c|c|c|c|c|c|c|c|c|c|c|}
\hline \multirow{2}{*}{$\begin{array}{l}\text { Islanding } \\
\text { Standard }\end{array}$} & \multirow{2}{*}{$\begin{array}{l}\text { Maximum ID } \\
\text { time (sec) }\end{array}$} & \multirow[t]{2}{*}{$V_{\max }(\%)$} & \multirow[t]{2}{*}{$V_{\min }(\%)$} & \multirow[t]{2}{*}{$f_{\max }(H z)$} & \multirow[t]{2}{*}{$f_{\min }(H z)$} & \multirow[t]{2}{*}{$Q_{f}$} & \multicolumn{4}{|c|}{ PMS (\%) } \\
\hline & & & & & & & \multicolumn{4}{|c|}{$\left(\Delta \mathrm{P} / \mathrm{P}_{\mathrm{DG}}\right)_{\min }\left(\Delta \mathrm{P} / \mathrm{P}_{\mathrm{DG}}\right)_{\max }\left(\Delta \mathrm{Q} / \mathrm{P}_{\mathrm{DG}}\right)_{\min }\left(\Delta \mathrm{Q} / \mathrm{P}_{\mathrm{DG}}\right)_{\max }$} \\
\hline IEEE 1547-2003 & 2 & 110 & 88 & 60.5 & 59.3 & 1 & -17 & 29 & 28 & 31.7 \\
\hline IEEE 929-2000 & 2 & 110 & 88 & 60.5 & 59.3 & 2.5 & -17 & 29 & 72 & 79.2 \\
\hline Korean std. & 0.5 & 110 & 88 & 60.5 & 59.3 & 1 & -17 & 29 & 28 & 31.7 \\
\hline VDE 0126-1-1 & 0.2 & 110 & 88 & 50.5 & 47.5 & 2 & -17 & 29 & -27 & 49 \\
\hline UL 1741 & 2 & 110 & 88 & 60.5 & 59.3 & 2.5 & -17 & 29 & 72 & 79.2 \\
\hline
\end{tabular}

Table 1 PMS for different islanding standards 


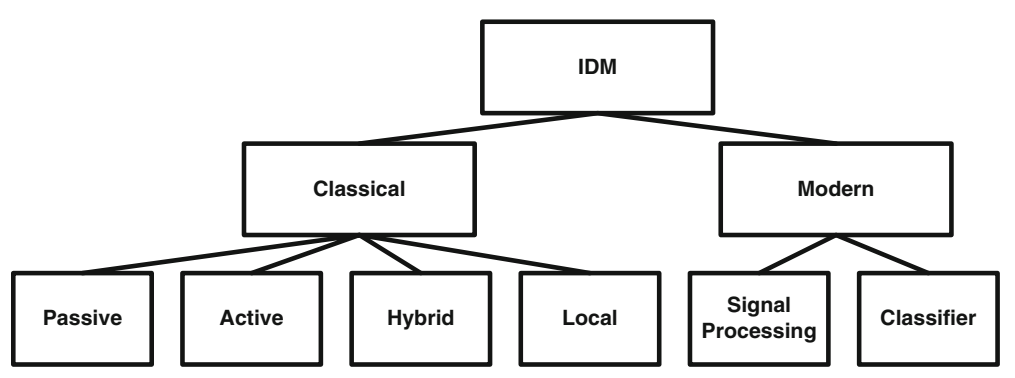

Fig. 4 IDM classification

islanding quickly but suffer nuisance tripping and have a large NDZ. Some of the significant passive methods are discussed below.

5.1.1.1 Over/under voltage (OVP/UVP) and over/ under frequency (OFP/UFP) From Fig. 2, the active and reactive power imbalance at PCC can be expressed as in (10-11). The technique basically measures $\Delta \mathrm{P}$ and $\triangle \mathrm{Q}$ at PCC just before the grid disconnection forming an island. If $\Delta \mathrm{P} \neq 0$, the voltage amplitude will change at PCC according to (12) and the OVP/UVP detects islanding on exceeding the limit. If $\Delta Q \neq 0$, the frequency will change suddenly at PCC according to (13). If it crosses the threshold value, then OFP/UFP detects islanding. This technique has a low NDZ but is simple and cheap $[15,21]$.

$$
\begin{aligned}
& \Delta P=P_{L O A D}-P_{D G} \\
& \Delta Q=Q_{L O A D}-Q_{D G} \\
& V^{\prime}=\sqrt{P_{D G} / P_{L O A D}} \times V \\
& Q^{\prime}=Q_{D G}=\left[\left(1 / \omega^{\prime} \times L\right)-\omega^{\prime} \times C\right] \times V^{\prime}
\end{aligned}
$$

5.1.1.2 Phase jump detection This technique uses the phase difference between the inverter output voltage and the inverter output current to detect islanding [22]. Under normal condition, the voltage and current are synchronized with each other through phase lock loop (PLL). In absence of main grid support, the voltage phase angle will have a sudden jump due to load phase angle creating a huge difference between voltage and current phase angle. If the difference crosses the specified limit, islanding is detected $[17,23]$. The equation of the phase-jump algorithm is as in (14).

$$
\arctan \left[\left(\Delta Q / P_{D G}\right) /\left(1+\Delta P / P_{D G}\right)\right] \leq \alpha
$$

5.1.1.3 Harmonic parameters This technique measures THD and the main harmonics $\left(3^{\text {rd }}, 5^{\text {th }}\right.$ and $\left.7^{\text {th }}\right)$ of the PCC voltage for ID [24]. Under normal condition, grid voltage almost matches with the PCC voltage causing negligible distortion $(T H D \approx 0)$. During islanded condition, the harmonics may increase due to transfer of inverter generated current harmonics to the load and presence of non-linearities in the transformer like magnetic hysteresis. The DG is disconnected if the measured values exceed its threshold [25].

5.1.1.4 Rate of change of frequency (ROCOF) On grid supply disconnection, the power imbalance causes transients in the islanded system leading to a gradual change in frequency. The rate of change of frequency is measured over a few cycles [26] and can be expressed as in (15). After a preset time delay, a trip signal is sent to the DG if this rate exceeds pre-set value. A trip setting of

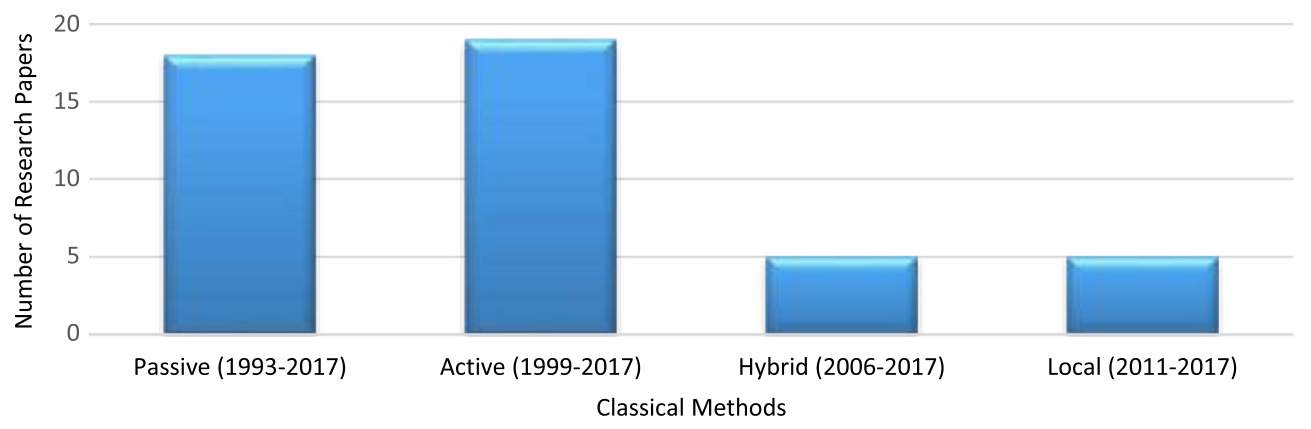

Fig. 5 Research trend in classical methods with time 
$0.3 \mathrm{~Hz} / \mathrm{s}$ with tripping time of $0.3 \mathrm{~s}-0.7 \mathrm{~s}$ is generally applied for small and medium DGs. However, in extreme frequency variations, the tripping time can be as less as four to five cycles [27].

$$
d f / d t=(\Delta P \times f) /(2 \times H \times G)
$$

5.1.1.5 Rate of change of power output (ROCOP) Due to grid disconnection, there is generally a large change in load. Hence, the power output of the DG changes. This technique monitors each variation in power output and integrates those variations over a specified sample period. In mathematical terms, it simply measures $(d p / d t)$ and is expressed as in (16). Islanding is detected when this variation exceeds threshold limit. This technique has an added advantage of detecting unsynchronized reconnection of the utility supply [26].

$$
d p / d t=\sum_{n=-t x}^{0}\left(P_{D G}\right)_{n}
$$

5.1.1.6 Impedance variation The impedance of a power island is considerably larger than that of the utility impedance. Upon islanding, the impedance of the islanded part will suddenly increase [28]. This change of impedance is used to detect islanding by comparing it to a specified value [29].

5.1.1.7 Miscellaneous The PLL in the inverter controller measures rate of change of voltage phase angle (ROCOVPA) at PCC to detect islanding in [30]. In [31], the magnitude of impedance at PCC is compared with that of a set of frequency dependent reference for ID. The oscillation frequency of synchronous generator is estimated in [32] by using a small window to detect islanding. ID based on rate of change of current sequence components at PCC is developed in [33]. Rate of change of frequency over reactive power at PCC for every half cycle is proposed for ID in [34]. In [35], passive ID using non ideal characteristics of voltage source inverter is shown with detection time of $100 \mathrm{~ms}$.

\subsubsection{Active methods}

To overcome the shortcomings of passive methods, active methods came to picture around 1997. In these techniques, a disturbance signal is provided to specific parameters at the PCC and their effect is monitored for ID. It incorporates some sort of feedback signal or control mechanism that checks any variation of certain parameters at the PCC. These methods have lower NDZ than passive methods but highly degrades the power quality of the grid. The notable methods are dealt below.

5.1.2.1 Slip mode frequency shift (SMS) SMS uses positive feedback to detect islanding. It applies positive feedback to the phase angle of the inverter current according to the deviation of frequency at PCC [36]. A typical SMS curve is so designed such that the increase in phase of the inverter is quicker than that of load with a unity power factor around the utility frequency region. Thus the line frequency becomes an unstable operating point for the inverter [22]. In islanded condition, the frequency and load phase angle varies with the curve. Islanding is detected when frequency crosses threshold [37].

5.1.2.2 Active frequency drift (AFD) This method slightly alters the waveform of inverter current fed into the PCC with respect to the main grid voltage [38]. This is mostly employed in PV power conditioner with microprocessor based controller [36]. The chopping fraction is calculated as a parameter for ID given by (17). This chopping frequency is low under normal condition and high in islanded condition. Islanding is detected when of crosses threshold limit. It has a limitation that all inverters must have same AFD mode else there is a chance of nullifying each other's effect leading to ID failure [39, 40].

$$
c f=2 \times t_{z} / T_{\text {vgrid }}
$$

5.1.2.3 Sandia frequency shift (SFS) This is an updated version of AFD with an inclusion of positive feedback to the frequency at PLL [41]. The chopping fraction is given as in (18). When grid is connected, a small change in frequency has no marginal effect but in islanded condition PCC frequency increases the frequency error which in turn increases the frequency of inverter. The process goes on until a threshold limit is reached and island is detected [36]. SFS has the smallest NDZ and is most efficient among the active techniques but it reduces the output power quality of the inverter. Moreover, positive feedback introduces noise and harmonics [42].

$$
c f=c f_{0}+K \times\left(f_{P C C}-f\right)
$$

5.1.2.4 Sandia voltage shift (SVS) This is similar to SFS where positive feedback is applied to the amplitude of voltage in PCC rather than frequency. This positive feedback alters the power and current output of the inverter. When in grid connected connection, the amplitude of voltage is not affected noticeably but in island condition, power output can expedite the voltage drift to detect islanding. SVS affects the maximum power tracking mechanism of the inverter due to alteration of power output $[43,44]$.

5.1.2.5 Negative sequence current injection This technique consists of injecting negative sequence current via voltage source converter (VSC) and monitoring negative 
sequence voltage at the PCC with the aid of unified three phase signal processor (UTSP). When connected to grid, it will have negligible impact on the PCC voltage but will have a considerable unbalance of PCC voltage during island condition [45].

5.1.2.6 Miscellaneous In [46], average absolute frequency deviation value of the islanded area with respect to inverter reference current is proposed for ID. High frequency signal injection of magnitude 0.01 p.u of line voltage is used in [47]. It complies to the connection standard as THD is almost $0.09 \%$. The estimation of transient stiffness of DG system by disturbing DG at distinct frequencies is proposed for ID in [48]. In [49], harmonic current at one of the frequency of the grid voltage is injected in grid altering the equivalent parallel impedance of the inverter for ID. The deviation between nominal and instantaneous voltage phase angle of DG is applied to inverter to detect islanding in [50]. In [51], frequency locked loop of inverter and frequency positive feedback for ID is employed.

\subsubsection{Hybrid methods}

These techniques became prevalent around 2003 to obtain both the advantages of passive and active methods. Hybrid techniques combine both active as well as passive detection techniques. The active techniques are applied only after islanding is detected by passive techniques. These methods have lower NDZ and does not significantly affect the power quality of grid. Some of the hybrid techniques are as follows:

\subsubsection{Positive feedback (PF) and voltage unbalance} (VU) This technique uses the PF (active) and VU (passive) to detect islanding. When the two are applied together, it eliminates the shortcomings of the individual techniques [52]. Basically, it monitors the three phase output voltages of the DG consistently to measure VU [53] given as per (19). Whenever any disturbance is applied to DGs, there is a spike in VU. Island is detected when this spike is above the set value. This technique is suitable for distinguishing between load switching and islanding condition.

$$
V U B=V_{+S q} / V_{-S q}
$$

5.1.3.2 Voltage and reactive power shift This technique measures the voltage variation over a time to obtain a covariance value (passive) given by (20) and then adaptive reactive power shift algorithm (ARPS) is employed for ID [54]. The reactive power shift or d-axis current shift is given according to (21). After suspicion of island, the additional reactive power shift accelerates the phase shift action which in turn leads to a fast frequency shift when islanding occurs.

$$
\begin{aligned}
& \left(T_{a v^{\prime}}, T_{v}\right)=E\left(T_{a v^{\prime}}^{(n)}-U_{a v}\right)\left(T_{v}^{(n)}-U_{v}\right) \\
& i_{d}=k_{d}\left(T_{a v^{\prime}}-T_{v}\right) / T_{v}
\end{aligned}
$$

5.1.3.3 Hybrid SFS and Q-f This technique is based on SFS and Q-f droop curve. An analytical formula has been used to optimally obtain gain of SFS given by (22) and the optimal solution is searched by bacterial foraging algorithm. The Q-f droop curve is then employed to detect islanding [55].

$$
K=\max \left\{\frac{2}{\pi}\left[\frac{Q_{f}\left(f_{0} / f^{2}-f / f_{0}\right)}{\left.1+Q_{f}^{2}\left(f_{0} / f-f / f_{o}\right)^{2}\right)}\right]\right\}
$$

5.1.3.4 Voltage and real power shift (RPS) This technique uses real power shift (active) and average rate of voltage change (passive) to detect islanding. The RPS is employed only when the passive technique is unsure about islanding scenario. This discards the need to inject disturbances frequently as in case of other active method. This method changes only the real power of DG satisfying the condition of unity power factor and also only at one DG unlike other positive feedback techniques [56].

\subsubsection{Local methods}

Local IDMs uses communication signals between utility and the DGs for ID. The frequency of such signal is usually kept low to avoid interference with other power system signals. The cost of practical application of these methods proves to be very high for a single DG installation. Hence, these techniques are costly for small distribution network. Another drawback of these methods is its high dependency on communication means [57]. Hence, these are not recommended for small DGs. However, the greatest advantage of these methods is zero NDZ.

5.1.4.1 Transfer trip scheme The underlying principle of this scheme is to monitor and obtain the status of the circuit breaker and reclosers which are capable of islanding a distribution system [58]. Figure 6 represents the working mechanism. When a disconnection of a substation occurs due to switching operation, the islanded areas are recognized by a central algorithm. After detection, signals are sent to these islanded areas for tripping the DGs. The central system can be avoided by sending the status signals to the DG directly from each monitoring point. The transfer trip scheme is also used with SCADA to allow additional control of DGs by utility for better coordination [57]. However, with too many reclosers and measuring points, transfer trip scheme can become quite tedious. Moreover, the algorithm requires the most updated information regarding 


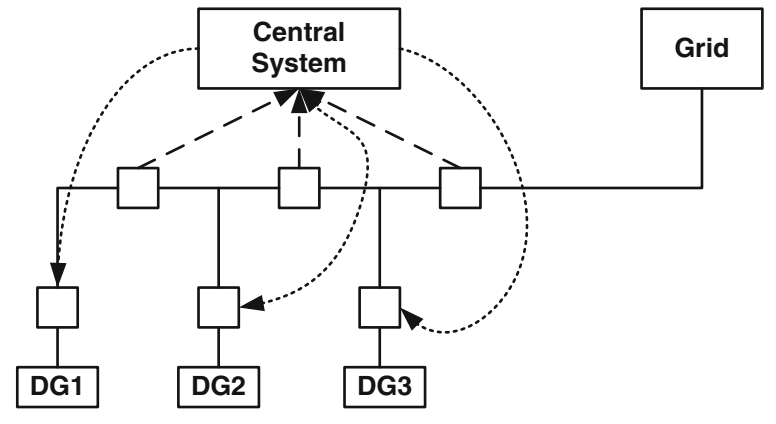

Fig. 6 Schematic diagram of transfer trip scheme

the distribution network topology confining the suitability of this scheme for fixed topology network [58].

5.1.4.2 PLCC This method utilizes the power line for signal transmission as shown in Fig. 7. It incorporates a signal generator (SG) attached to the secondary side of substation transformer for continually broadcasting of signal which is received by the receiver (R) at the DG end. When any island is formed, this communication gets hindered and the CB of the DG gets tripped. This method is suitable for microgrids with high DG concentration and is also independent of the network topology. The feasibility of PLCC in ID is demonstrated in $[59,60]$ where field tests have been conducted.

Table 2 shows the comparison between various classical IDMs.

\subsection{Modern}

The modern methods include methods which exclusively use signal processing techniques and classifiers but the backbone of these methods is the classical IDMs mostly passive. These methods improve the performance of the classical IDMs.

\subsubsection{Signal processing methods}

These methods started appearing in literature in 2005 when signal processing was acquiring its foothold in the area of power system. These methods extensively employ signal processing tools to extract features of signals obtained for ID. Significant tools among these are Wavelet transform (WT), Stockwell transform (ST), Hilbert

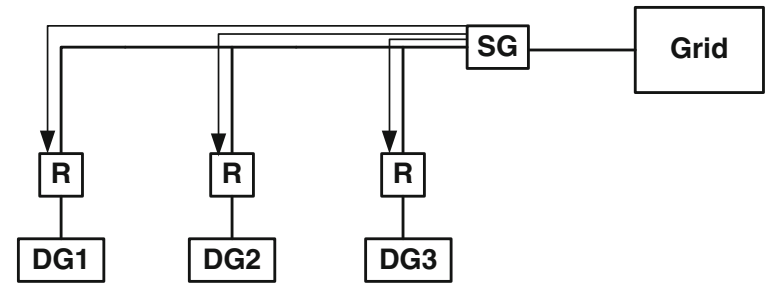

Fig. 7 Schematic diagram of PLCC scheme
Huyang transform (HHT), time-time transform (TT), mathematical morphology (MM), etc. The number of research papers in this field is depicted in Fig. 8.

5.2.1.1 WT WT has been extensively used for signal processing in the last two decades. Its main advantage is its ability to expand a signal in frequency domain while retaining time information [61]. Hence applications where both time and frequency is required, applies WT. Such applications include fault detection, power quality measurement, power system protection, etc. [62]. There are several variants of WT available. Depending on the type of application one method is preferred over another. There are primarily three variants- continuous wavelet transform (CWT), discrete wavelet transform (DWT) and wavelet packets transform (WPT).

\section{CWT}

In this, the given signal is correlated with a scaled and shifted version of a function called as mother wavelet given by (23). The CWT is given by (24) which represents the degree of similarity between the analyzed function and the mother wavelet. In [63] CWT is employed to first analyze grid connected voltage. Islanding is detected by wavelet de-noising and non-stationary signal detection.

$$
\begin{aligned}
& \left.\Psi_{a, b}(t)=(1 / \sqrt{a}) \times \Psi((t-b) / a)\right) \\
& C(a, b)=\int_{-\infty}^{+\infty} u(t) \Psi_{a, b}(t) d t
\end{aligned}
$$

\section{DWT}

CWT provides coefficients for all scales and transformations leading to a notorious amount of computational burden. To overcome this, DWT is employed which transforms into several frequency bands and has better resolutions at low frequency rather than at high frequency. Here, the scaling parameters and translational parameters are modified in powers of two known as dyadic dilations and translations. The discrete mother wavelet is given according to (25) where $\mathrm{a}_{0}>1$ and $b_{0}>0$. The DWT can then be given as in (26).

$$
\begin{aligned}
& \Psi q, r(t)=a_{0}^{-q / 2} \times \Psi\left(\left(t-r a_{0}^{q} b_{0}\right) / a_{0}^{q}\right) \\
& D(q, r)=\int_{-\infty}^{\infty} u(t) \Psi_{q, r}(t) d t
\end{aligned}
$$

Mallat proposed an algorithm for implementing DWT known as Mallat algorithm or Mallat's multi resolution analysis (MRA) [64]. Here, the signal is decomposed by 
Table 2 Comparison of classical methods

\begin{tabular}{|c|c|c|c|c|c|c|c|}
\hline Classical IDM & Main method & Reference & Detection time & DG system considered & Multiple DG considered & Strength & Shortcoming \\
\hline \multirow[t]{5}{*}{ Passive } & PJD & 22 & $0.1 \mathrm{~s}$ & Inverter based & No & \multirow{5}{*}{$\begin{array}{l}\text { Low detection } \\
\text { time }\end{array}$} & \multirow[t]{5}{*}{ High NDZ } \\
\hline & Harmonic parameters & 24 & Less than $2 \mathrm{~s}$ & Inverter based & Yes & & \\
\hline & ROCOF & 27 & 0.5 & Synchronous & Yes & & \\
\hline & ROCOP & 26 & $26 \mathrm{~ms}$ & Not specified & No & & \\
\hline & Impedance variation & 29 & - & Synchronous & No & & \\
\hline \multirow[t]{5}{*}{ Active } & SMS & 37 & $0.37 \mathrm{~s}$ & VSC & No & \multirow[t]{5}{*}{ Low NDZ } & \multirow{5}{*}{$\begin{array}{l}\text { Degrades power } \\
\text { quality }\end{array}$} \\
\hline & AFD & 38 & $928 \mathrm{~ms}$ & Inverter based & No & & \\
\hline & SFS & 36 & $0.10 \mathrm{~s}$ & VSC & No & & \\
\hline & sVs & 43 & $0.231 \mathrm{~s}$ & Inverter based & No & & \\
\hline & $\begin{array}{l}\text { Negative sequence } \\
\text { current injection }\end{array}$ & 45 & $60 \mathrm{~ms}$ & VSC & No & & \\
\hline \multirow[t]{4}{*}{ Hybrid } & $\mathrm{PF}$ and $\mathrm{VU}$ & 52 & $0.15 \mathrm{~s}$ & Synchronous & Yes & \multirow{4}{*}{$\begin{array}{l}\text { Small NDZ and } \\
\text { detection time }\end{array}$} & \multirow{4}{*}{$\begin{array}{l}\text { Slightly Degrades } \\
\text { power quality }\end{array}$} \\
\hline & $\begin{array}{l}\text { Voltage and reactive } \\
\text { power shift }\end{array}$ & 54 & - & Inverter based & No & & \\
\hline & Hybrid SFS and Q-f & 55 & - & Inverter based & No & & \\
\hline & RPS & 56 & - & Wind & Yes & & \\
\hline \multirow[t]{2}{*}{ Local } & Transfer trip & 58 & - & $P V$ & Yes & \multirow[t]{2}{*}{ Zero NDZ } & \multirow[t]{2}{*}{ High cost } \\
\hline & PLCC & 60 & - & PV & Yes & & \\
\hline
\end{tabular}

passing through high pass filters and low pass filters to obtain low frequency content (known as approximation and denoted by A) and high frequency content (called details and denoted as D) respectively as shown in Fig. 9. This process is repeated continuously until a desirable level is reached.

In [65], a hybrid ID method is used where the PV inverter introduces high frequency components and then DWT is applied. The islanding is detected between 17 and $26 \mathrm{~ms}$ and is revealed at $5^{\text {th }}$ decomposition level with biorthogonal 1.5 as the selected wavelet owing to its better resolution and response time for the considered system. Daubechies mother wavelet analysis of frequency and voltage is used in [66] to detect islanding event for a DG unit of a southern Taiwan petroleum company. The method proves to be feasible and robustness with ID time of $0.05-0.1 \mathrm{~s}$. Daubechies db4 based DWT is proposed in [67] where the negative sequence current and voltage of DGs are analyzed. Islanding is detected by detailed coefficient at level 1 within 1 cycle. [68] suggests a db4 DWT based passive ID method without any NDZ. The central idea is to detect the post islanding spectral changes of the higher frequency components of PCC. ID of induction type wind turbines using db5 based DWT on a wind turbine simulator is presented in [69] where islanding within less than $0.2 \mathrm{~s}$ is achieved. Wavelet MRA is used in [70] for ID by decomposing the voltage signals of the DGs into various scales and generating a series of wavelet

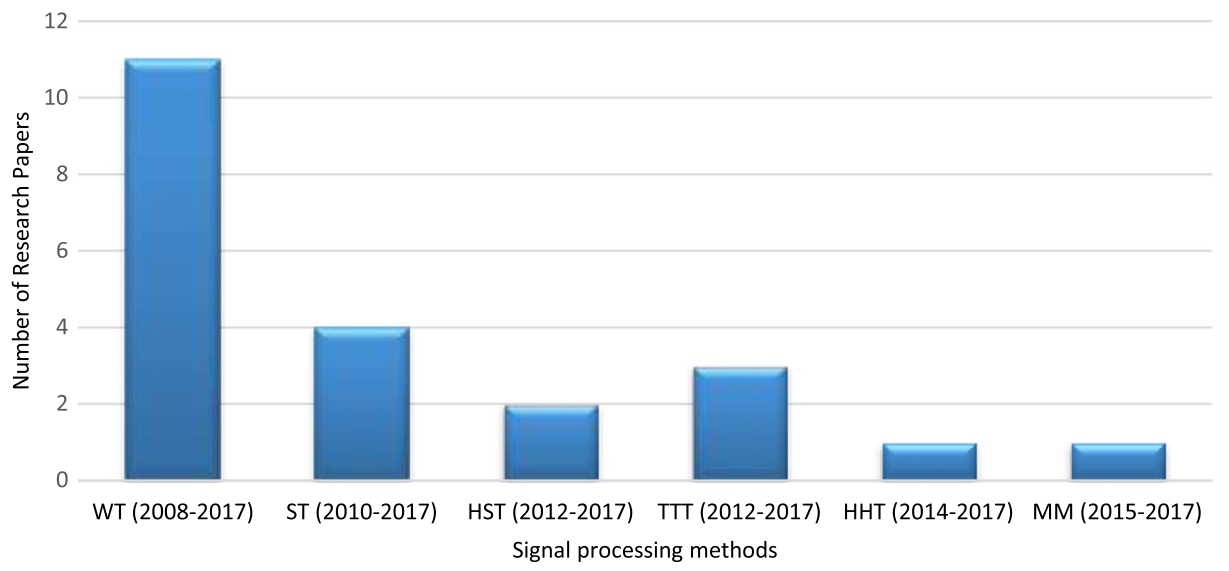

Fig. 8 Research trend in signal processing methods with time 


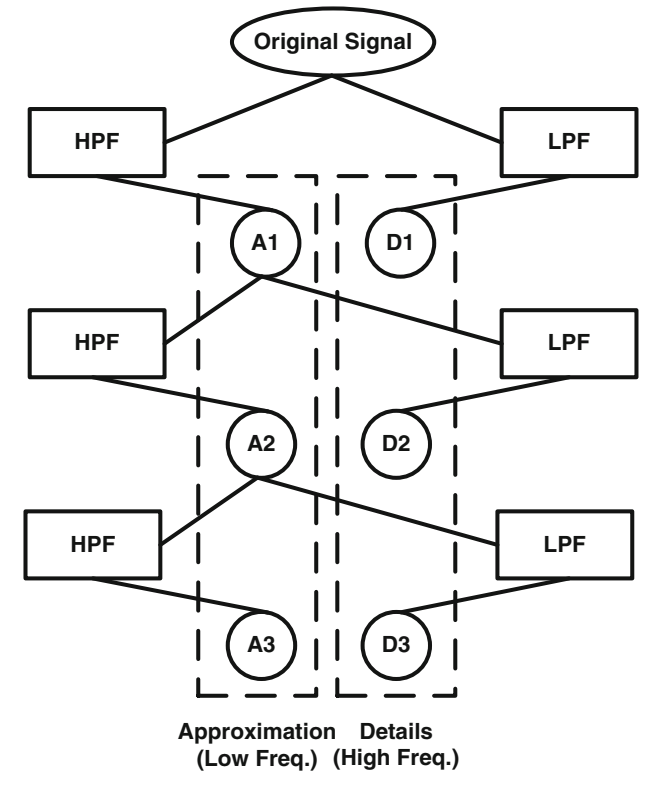

Fig. 9 Schematic diagram of MRA

coefficients corresponding to each scale. The ratio of WCs on scales 2 and 3 are used to detect islanding. The results imply that the features extracted by MRA indicate the variations in high frequency harmonic components which can be used as a potential parameter for islanding. DWT of voltage signal at PCC is used for feature extraction in [71] for ID. In [72] ID by wavelet singular entropy (WSE). The detailed coefficients at different levels of decomposition of the three phase DG voltage are acquired for generating a singular value matrix and WSE for each phase. Islanding is detected by adding the WSE of each phase to obtain WSE index (WSEI). The developed technique has a high detection speed with detection time of half cycle. [73] employs DWT based feature extraction of negative sequence of PCC voltage signal to detect islanding in $25 \mathrm{~ms}$.

\section{WPT}

WPT is similar to DWT except for the fact that WPT gives equal resolution to both low as well as high frequency. In WPT, the approximations as well as details are decomposed as shown Fig. 10. In [74], WPT extracts significant features of ROCOP of DGs. For this, a node rate of change of power index (NROCOPI) is calculated to compare the power change at individual WPT sub-bands considering $\mathrm{d} 10$ as the basis function. Under islanded condition, NROCOPI has a notable value at the lowest frequency band i.e. node zero of the wavelet packet tree.

5.2.1.2 ST The extension of the concept of wavelet transform is ST. The ST converts time domain into twodimensional frequency translation domain. The modulating sinusoids are fixed in accordance to time axis

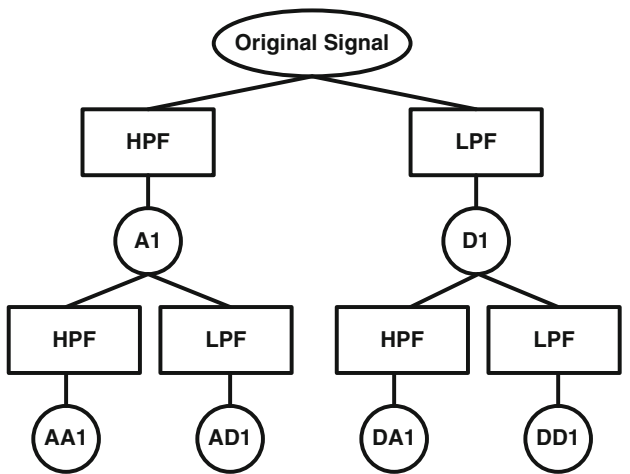

Fig. 10 Schematic diagram of WPT

while the localizing scalable window translates and dilates. The local spectral characteristics can be defined from the obtained phase-frequency-time spectrum and amplitude-frequency-time spectrum [75]. The ST of a signal can be represented as in (27) where $\mathrm{w}$ is positive and Gaussian and can be represented as in (28). The prime advantage of it is its simple nature. It simplifies the concept of multiresolution concept of wavelet transform and requires a little of extra knowledge except that of short time Fourier transform [76].

$$
\begin{aligned}
& S(\tau, f r)=\int_{-\infty}^{\infty} u(t) w(\tau-t, f r) e^{-2 i n f f t} d t \\
& w(\tau-t, f r)=(|f r| / d \sqrt{2 \pi}) e^{-0.5(f r(\tau-t) / d)^{2}}
\end{aligned}
$$

ST based ID for DG hybrid system is proposed in [77]. In this, the negative sequence of PCC voltage is analyzed by ST, energy content and standard deviation of $\mathrm{S}$ contour is computed and the results are compared with WT. The results clearly prove the advantages of ST over WT. In [78], based on spectral energy content of the negative sequence of voltage and current, ST based cumulative sum detector (CUSUM) is developed for ID. ST of voltage signal at PCC is used for feature extraction in [71] for ID. [73] employs ST based feature extraction of negative sequence of PCC voltage signal to detect islanding in $26 \mathrm{~ms}$.

5.2.1.3 HST The drawback of S-transform lies in its disability in localizing in the time domain momentary phenomenon like sag and swell [79]. To strike out this shortcoming, HS transform is used which uses a pseudo-Gaussian hyperbolic window to achieve better time and frequency resolutions at high and low frequency. The hyperbolic window is frequency dependent 
in its shape besides its height and width. Due to this asymmetrical window, better resolution is obtained. In [71], islanding in a hybrid DG system is recognized by HST. The standard deviation and energy content of HST contour is presented to show its superiority over WT and ST in case of islanding for both noise as well as noiseless scenarios. [73] employs HST based feature extraction of negative sequence of PCC voltage signal to detect islanding in $22 \mathrm{~ms}$.

5.2.1.4 TTT In this transform, different frequency components are concentrated at different position. The higher frequencies are concentrated around the localization point than the lower frequencies. This enables to filter the time-time plane besides timefrequency plane [80]. The TTT is derived by inverse Fourier transform of ST as in (29). The TT is a matrix of redundant information in time-time domain.

$$
T T(t, \tau)=\int_{-\infty}^{\infty} S(\tau, f r) e^{2 i \pi f r t} d(f r)
$$

TTT is employed in [81] where the pattern obtained by TTT of the three phase disturbances depicts unique signatures clearly. It is observed that individual event exhibits a unique pattern which is used to detect islanding. In [71] the graphical result analysis depicts the TTT capability of ID and localization of islanding disturbances over WT, ST and HST in a hybrid DG system. The performance is analyzed by computing energy content and standard deviation of the transformed signal. [73] employs TTT based feature extraction of negative sequence of PCC voltage signal to detect islanding in $25 \mathrm{~ms}$.

5.2.1.5 HHT The HHT comprises of two stages. In first stage, by applying empirical mode decomposition (EMD), the concerned signal is decomposed into intrinsic mode functions (IMFs) to obtain meaningful instantaneous amplitudes and frequencies [82]. The IMFs are arranged in descending order of frequency. In the second stage, Hilbert transform is applied on individual IMFs to obtain instantaneous amplitude and frequency versus time. Though HHT representations are more meaningful physically, yet they are less suitable for signals possessing close frequency components as well as identifying obtaining transition times for sudden waveform changes [83]. HHT is employed in [84] to obtain zero NDZ for inverter based islanding. The first component of per-unit one phase PCC voltage is found by EMD process and is used for ID. For this, one-cycle data window is employed. From simulations result, the ID is obtained to be less than 2 cycles. The effectiveness is further proved for multiple DG systems under various configurations. The simplicity, robustness against noise and straightforwardness of HHT is clearly shown.

5.2.1.6 MM Basically, morphological filters incorporate nonlinear signal transformation tools for modifying the shapes of signals. MM originates from integral geometry and set theory. The WT, HST and TTT have greater computational complexity for harmonics and transients. Moreover, the assumed periodicity of the signal degrades the detection accuracy. Unlike these, mathematical morphology simply includes addition and subtraction of signals. By employing a smaller data window, abnormalities can be quickly detected [85]. MM is used to detect islanding by analyzing the negative sequence component of voltage signal at PCC for a hybrid DG system with solar and wind integrated IEEE 30 bus system [73]. It detects islanding within $22 \mathrm{~ms}$ proving to be more effective and feasible than WT, ST and TT for ID under noise free as well as noisy circumstances and also under the conditions of harmonics. For comparing, an energy based technique considering a suitable threshold value is employed.

Table 3 shows the comparison between various signal processing IDMs.

\subsubsection{Classifier methods}

Setting a suitable threshold for ID is a Herculean task. If the threshold value is less sensitive, islanding condition will not be detected accurately while setting a high sensitive threshold value will cause nuisance relay tripping. Therefore, a suitable tool is needed in order to achieve high sensitivity as well as high accuracy. Classifiers prove to accomplish such task effectively in case of ID. Such islanding classifiers like Artificial Neural Network (ANN), fuzzy logic (FL), decision tree (DT), artificial neuro-fuzzy inference system (ANFIS), static vector machine (SVM) etc. became prevalent around 2010 and are the latest ID area nowadays. The number of research papers in this field is depicted in Fig. 11.

5.2.2.1 DT DT is a tool employed for pattern recognition that segregates input vectors into discrete grades and generates the output in a binary tree-resembling structure., It can disintegrate a complicated decision making process into several simple decisions. The basic logic of DT is explained in Fig. 12. The first step involves splitting of the root node (i.e. the node representing the entire data set) into child nodes on the basis of a predictor variable. The node that possesses the purest data is selected as the child node that can further be split. A node that cannot be further split is called leaf node. The DT performs the splitting process for classification until a leaf node is reached. The DT possesses the advantage of faster training process than other pattern recognition methods [86]. 
Table 3 Comparison of signal processing methods

\begin{tabular}{|c|c|c|c|c|c|c|c|}
\hline $\begin{array}{l}\text { Signal processing } \\
\text { method }\end{array}$ & Ref. & DG type & $\begin{array}{l}\text { Multiple DG } \\
\text { considered }\end{array}$ & Analyzed signal & $\begin{array}{l}\text { Run on } \\
\text { time }\end{array}$ & $\begin{array}{l}\text { Strength of } \\
\text { the method }\end{array}$ & $\begin{array}{l}\text { Shortcoming of } \\
\text { the method }\end{array}$ \\
\hline CWT & 63 & - & - & Target DG voltage & 0.6 & $\begin{array}{l}\text { Coefficients for all scales } \\
\text { and transformations is } \\
\text { obtained }\end{array}$ & Computational burden \\
\hline \multirow[t]{3}{*}{ DWT } & 65 & PV & No & PCC voltage & $17-26 \mathrm{~ms}$ & \multirow{3}{*}{$\begin{array}{l}\text { Better low frequency } \\
\text { resolutions }\end{array}$} & \multirow[t]{3}{*}{ Computational complexity } \\
\hline & 67 & PV & No & PCC frequency & $\begin{array}{l}2.5 \text { power } \\
\text { freq cycle }\end{array}$ & & \\
\hline & 68 & PV & No & Target DG voltage & $\begin{array}{l}2.5 \text { cycle } \\
(0.05 \mathrm{~s})\end{array}$ & & \\
\hline WPT & 74 & Wind & No & ROCOP at DG & $200 \mathrm{~ms}$ & $\begin{array}{l}\text { Equal resolution for low } \\
\text { and high frequency }\end{array}$ & $\begin{array}{l}\text { Time-frequency localization } \\
\text { decrease with increase in } \\
\text { decomposition levels. }\end{array}$ \\
\hline \multirow[t]{2}{*}{ ST } & 73 & PV and wind & Yes & $\begin{array}{l}\text { PCC voltage } \\
\text { negative sequence }\end{array}$ & $26 \mathrm{~ms}$ & \multirow[t]{2}{*}{$\begin{array}{l}\text { Provides simplified } \\
\text { multiresolution }\end{array}$} & \multirow[t]{2}{*}{$\begin{array}{l}\text { Fails in localization of } \\
\text { momentary phenomenon }\end{array}$} \\
\hline & 77 & $\begin{array}{l}\text { PV, fuel cell } \\
\text { and wind }\end{array}$ & Yes & $\begin{array}{l}\text { PCC voltage } \\
\text { negative sequence }\end{array}$ & - & & \\
\hline \multirow[t]{2}{*}{ HST } & 71 & $\begin{array}{l}\text { PV, fuel cell } \\
\text { and wind }\end{array}$ & Yes & PCC voltage & - & \multirow{2}{*}{$\begin{array}{l}\text { Better time and frequency } \\
\text { resolutions for high and } \\
\text { low frequency }\end{array}$} & \multirow[t]{2}{*}{$\begin{array}{l}\text { Window may not incorporate } \\
\text { all signals }\end{array}$} \\
\hline & 73 & $P V$ and wind & Yes & $\begin{array}{l}\mathrm{PCC} \text { voltage } \\
\text { negative sequence }\end{array}$ & $22 \mathrm{~ms}$ & & \\
\hline \multirow[t]{2}{*}{$\pi T$} & 71 & $\begin{array}{l}\text { PV, fuel cell } \\
\text { and wind }\end{array}$ & Yes & PCC voltage & - & \multirow{2}{*}{$\begin{array}{l}\text { Better understanding of } \\
\text { time-local properties of } \\
\text { the time series }\end{array}$} & \multirow[t]{2}{*}{$\begin{array}{l}\text { Inappropriate low-frequency } \\
\text { Localization }\end{array}$} \\
\hline & 73 & PV and wind & Yes & $\begin{array}{l}\text { PCC voltage } \\
\text { negative sequence }\end{array}$ & $25 \mathrm{~ms}$ & & \\
\hline HHT & 84 & $\begin{array}{l}\text { Inverter } \\
\text { based }\end{array}$ & Yes & PCC voltage & $\begin{array}{l}\text { Less than } \\
2 \text { cycles }\end{array}$ & $\begin{array}{l}\text { Provides physical } \\
\text { representation of data }\end{array}$ & $\begin{array}{l}\text { Less suitable for close } \\
\text { frequency components signals }\end{array}$ \\
\hline $\mathrm{MM}$ & 73 & PV and wind & Yes & $\begin{array}{l}\text { PCC voltage } \\
\text { negative sequence }\end{array}$ & $22 \mathrm{~ms}$ & $\begin{array}{l}\text { Less computational } \\
\text { complexity }\end{array}$ & $\begin{array}{l}\text { Reconstruction of the } \\
\text { original signal is not possible }\end{array}$ \\
\hline
\end{tabular}

ID for any possible network topology, DG operating condition and DG penetration is proposed in [87] where 11 system parameter indices are evaluated via numerous event analyses and then DT is employed to extract feature from huge data sets of these indices to detect islanding.

The proposed method has $83.33 \%$ accuracy. In [88], islanding instances are classified with DT algorithm. Adaptive boosting technique is employed to reduce the classification error rate. Owing to this boost algorithm,
$100 \%$ accuracy is reached with negligible NDZ. [89] used DWT and DT for ID based on extracted current and voltage transient features for a medium voltage distribution system incorporating multiple DGs. The detection time is $24 \mathrm{~ms}$ with $99.22 \%$ accuracy and $95 \%$ confidence. The work has been extended for synchronous and induction type DGs in [90] where the effect of noise is being considered. The accuracy in case of noise is 96.11\% with $99 \%$ confidence and 3 cycle detection time. In [91], the classifying features for training the DT is

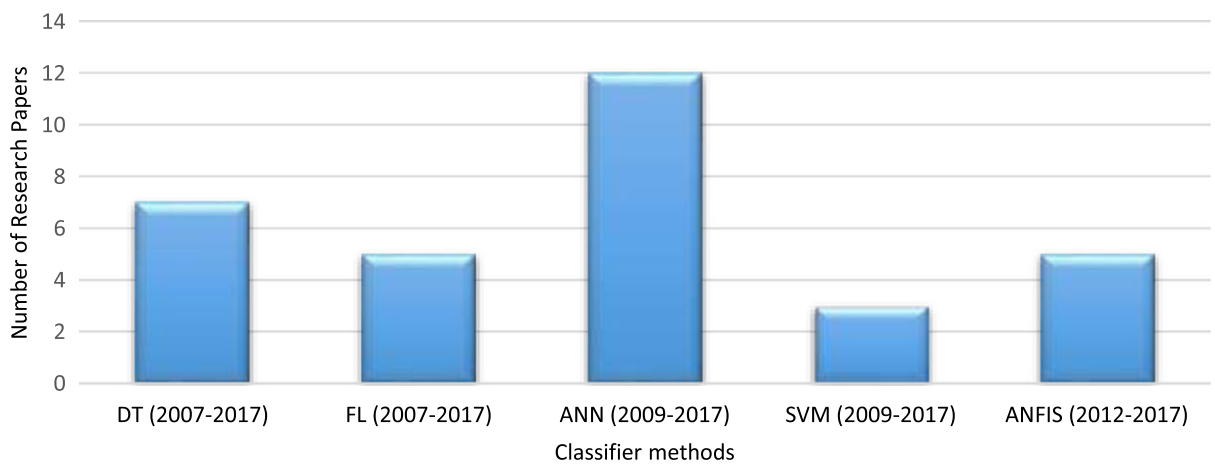

Fig. 11 Research trend in classifier methods with time 


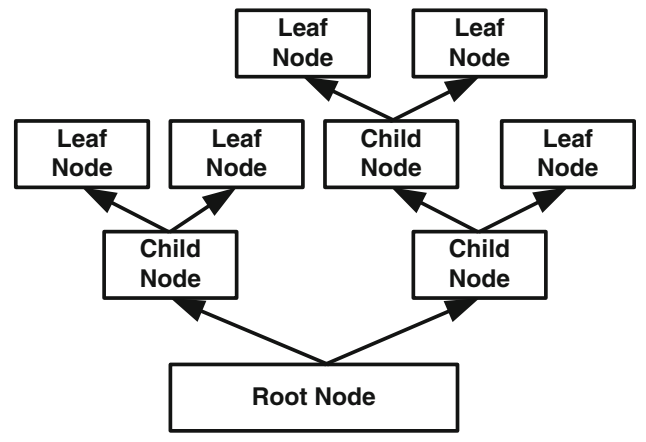

Fig. 12 Schematic diagram of DT

also acquired by DWT of transient signals for ID in a CIGRE distribution system. Among 162 relay designs, a V-db4-D3 relay is selected for ID with $98 \%$ accuracy. In [92], harmonic content and ROCOF of the equivalent reactance as seen at DG location is used as input of DT for a grid connected WSCC three machine 9 bus test system. [93] uses DT and voltage and frequency positive feedback for ID based on 6 feature indices.

5.2.2.2 FL FL is a superset of Boolean logic that takes into account the idea of partial truth i.e. values between purely true and purely false [94]. It involves three steps primarily- fuzzification, evaluation of rules and defuzzification. Fuzzification step involves describing membership functions. The FL rules are then applied. Finally, in the deffuzification stage crisp results are obtained. The basic configuration of a FL system is shown in Fig. 13.

A fuzzy based relay based on multi criteria algorithm for ID is proposed in [95]. It monitors the variations in ROCOF, ROCOP and voltage at PCC and through fuzzy logic rules islanding is detected. A DT based fuzzy rule for ID is discussed in [96]. A crisp DT does the initial classification of 11 features after which the fuzzy membership functions are developed to transform the DT into fuzzy rules. The classification rate is found to be $100 \%$ with and without noise. Features extracted by ST

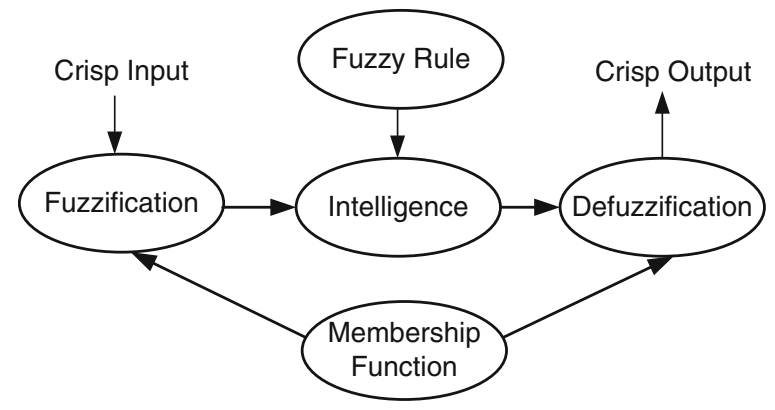

Fig. 13 Schematic diagram of FL are fed into a fuzzy expert system (FES) for islanding classification in [96] with an average accuracy of $99.8 \%$. [97] proposes a fuzzy adaptive phase drift ID algorithm where the nonlinear relationship between different load characteristic and frequency drift at PCC is developed for fuzzy optimization. A fuzzy load parameter estimation (FLPE) is used to tune adaptively the SFS parameters for ID in [98].

5.2.2.3 ANN The fundamental element of ANN is a collection of processing blocks commonly known as nodes or neurons. It can also be interpreted as a directed graph in which a transfer function is executed on each node according to (30).

$$
y_{m n}=\varsigma_{n n}\left(\sum_{j=1}^{n n} w_{n n j} x_{j}-b_{n n}\right)
$$

The process of adjusting the weights through some appropriate algorithm is called training or learning [99]. The schematic diagram of a simple ANN is shown in Fig. 14.

A hybrid ID method based on ANN is developed in [100]. The passive part incorporates analyzing 6 indices at target DG location while the active part incorporates alteration of positive feedback of active/reactive power. The false detection rate is $11.1 \%$. A neuro wavelet ID technique is developed in [101] in which the transient voltage signals have first been analyzed by DWT to extract feature vectors and then fed to train an ANN. Novel voltage signals of a multiple inverter based DG were tested with the trained ANN and an accuracy of 97.55\% was achieved. Similar work has been done with three phase current signal combined into one modal signal of a 9 MVA wind based test system in [102] to obtain $0 \%$ classification error rate. Another application of ANN in ID is found in [103]. Voltage and current signals at PCC of a wind farm power station are measured and processed through Fourier transform to extract second harmonic. The symmetrical components of this second harmonic are then used for training an ANN. The method detects islanding within 2 cycles with high confidence.

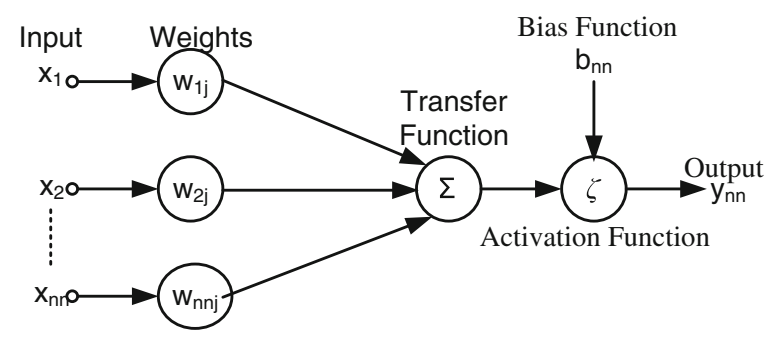

Fig. 14 Schematic diagram of ANN 
Besides the core application of ANN, its variants like extended neural network (ENN), back propagation neural network (BPNN), self-organizing map (SOM), probabilistic neural network (PNN) and modular probabilistic neural network (MPNN) have also found application in ID. PNN is proposed in [104], where features extracted by DWT are fed to PNN classifier for recognizing islanding events. The method was also tested for different sampling frequency and feature set. The average accuracy of the proposed method is $89.76 \%$. In [105], SOM is applied for ID. The papers propose application of SOM for classification of different islanding from non-islanding scenarios by analyzing the input signal of automatic load frequency controller (ALFC) of a distributed resource through it. The output of SOM sends a control signal to the automatic voltage regulator (AVR) for an under voltage relay tripping. The misclassification rate of [105] is $2.08 \%$ while in [106] it is $1.81 \%$. [107] proposes ENN with active and passive multi variable detection techniques for ID. The peak value and frequency of the output voltage of power conditioner, the phase difference between current and voltage of the power conditioner is obtained by current and voltage feedback signals and fed to ENN for islanding classification. The simulation results prove the feasibility of the method. MPNN is used in [108] for islanding and power quality disturbance classification for a hybrid DG system. [109] combines chaos synchronization and type 2 ENN for ID for a grid connected Chua's circuit based PV system. It has $98.4 \%$ accuracy. BPNN along with WPT is used in [110] to detect islanding based on normalized logarithmic energy entropy. The islanding is detected within $40 \mathrm{~ms}$.

5.2.2.4 SVM ANN has certain disadvantages. The learning process may get halted due to the multimodal nature. Further, the generalization abilities rely on the chosen architecture. These disadvantages are overcome by SVM. In SVM algorithm, the separating margin in between the classes, defined for a set of data pairs: class and input vector $\left(c_{j}, v_{j}\right)$, for $j=1 \ldots . . m$, a special type of training program is implemented. The input vectors $\mathrm{v}_{\mathrm{j}}$ is mapped into a high dimensional space by some nonlinear mapping function also called activating function $(\alpha)$, to construct an optimal hyperplane [111]. Figure 15 shows the schematic structure of SVM.

SVM is used to classify islanding events in a distribution system obtained from CIGRE MV system in [104] From simulated current signals at PCC, features are extracted by DWT for the training of SVM. The overall accuracy of SVM is found to be $78 \%$. The results were also compared with DT and PNN which proved its inferiority. The application of SVM in ID for a hybrid DG

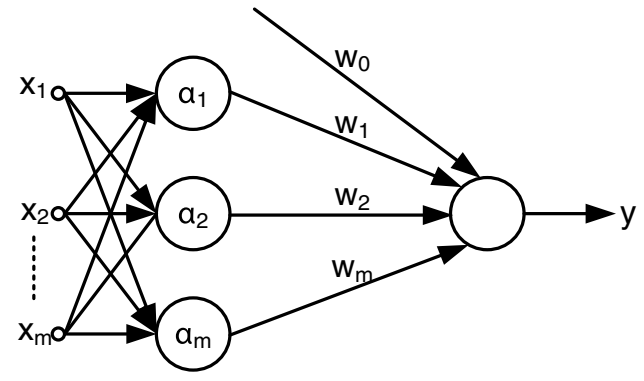

Fig. 15 Schematic diagram of SVM

system is developed in [108]. S transform is used to construct a matrix containing important information like magnitude, frequency and phase. Ten features are then extracted which is then applied to SVM for classification of islanding and PQ disturbances events. The overall accuracy obtained is $97.67 \%$. A comparative analysis of application of SVM along with ST, HST, TTT and MM to detect islanding is given in [73]. It is seen that MM based SVM is best among all the other with $98.7 \%$ accuracy.

5.2.2.5 ANFIS ANFIS evolved by combining the advantages of ANN and FL. The process of pattern recognition and adaptation to cope with the changing conditions is accomplished by the neural network while the task of uncertainty and imprecision is handled by the fuzzy system. The basic structure of ANFIS is shown in Fig. 16. In the first stage, an initial fuzzy model is developed from the rules derived from the output-input relationship of the concerned model. In the second stage, the rule of the developed fuzzy model is adjusted by the neural network to produce the final results [112].

The advantage of ANFIS in reducing the NDZ and keeping the power quality unchanged is clearly demonstrated in [113, 114]. A passive ID through classification of various indices like voltage, current, etc. by ANFIS is shown in [115]. Similarly, wavelet based ANFIS is also used in active ID technique through d axis signal injection for a UL 1741 test configuration [116]. A hybrid islanding technique using ANFIS is implemented in [117] based on probability of islanding (PoI) values on Smart grid side.

Table 4 shows the comparison between various classifier IDMs.

The comparisons between classical and non-classical methods are given in Table 5 . It can be inferred that none of the classical methods is accurate for any power system topology as every method has its own merits and demerits. Technical and financial performance of these methods comes at the cost of each other. However, with extensive researches in islanding domain, 


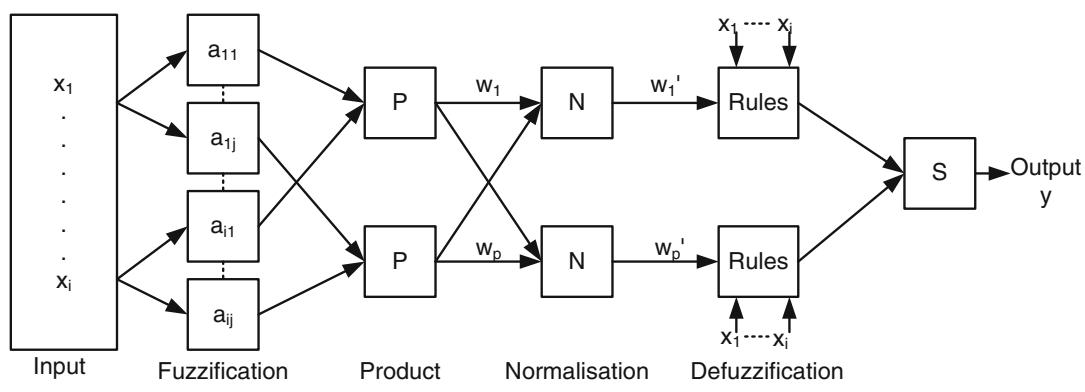

Fig. 16 Schematic diagram of ANFIS

the modern methods are eliminating these differences gradually. The modern methods are gaining popularity for their high accuracy and low detection time as evident from Fig. 17. which represents the percentage of research papers of various IDM. It can be expected that with more advancement in signal processing and learning algorithms, the robustness of the IDMs will elevate. Therefore, the companies or researchers should be properly acquainted with these methods as well as their system topology to improve the performances of the methods for accomplishing faster and accurate islanding.

\section{Conclusion}

A comprehensive survey of available IDMs has been dealt with in this paper. A brief introduction of each method is provided so that the shifting of the research ideas of the islanding methods can be comprehended vividly. The furtherance of each IDM with time is also discussed. The appropriateness of IDMs has been analyzed in terms of NDZ, run on time, nuisance tripping percentage, applicability in multi DG system and implementation cost. The PMS of islanding test systems have also been evaluated to materialize NDZ concept. Since there is no uniform islanding test bed, the IDMs are not

Table 4 Comparison of classifier methods

\begin{tabular}{|c|c|c|c|c|c|c|c|c|}
\hline Classifier & Ref. & $\begin{array}{l}\text { Signal processing } \\
\text { method applied }\end{array}$ & $\begin{array}{l}\text { No. of input } \\
\text { features }\end{array}$ & DG type & $\begin{array}{l}\text { Multi DG } \\
\text { considered }\end{array}$ & $\begin{array}{l}\text { Nuisance tripping } \\
\text { percentage }\end{array}$ & $\begin{array}{l}\text { Strength of } \\
\text { the classifier }\end{array}$ & $\begin{array}{l}\text { Shortcoming of } \\
\text { the classifier }\end{array}$ \\
\hline \multirow[t]{3}{*}{$\overline{\mathrm{DT}}$} & 87 & - & 2 & Synchronous & Yes & 16.6 & \multirow[t]{3}{*}{ Fast training } & \multirow{3}{*}{$\begin{array}{l}\text { Unfit for cases having lot } \\
\text { of un-correlated variables }\end{array}$} \\
\hline & 91 & DWT & 6 & Not specified & Yes & 2 & & \\
\hline & 92 & - & 7 & Synchronous & Yes & 0 & & \\
\hline \multirow[t]{2}{*}{$\mathrm{FL}$} & 95 & - & 2 & Synchronous & No & 0 & \multirow[t]{2}{*}{ Easily interpretable } & \multirow[t]{2}{*}{ Not robust } \\
\hline & 96 & - & 3 & Synchronous & No & 0 & & \\
\hline \multirow[t]{3}{*}{ ANN } & 100 & - & 2 & Synchronous & Yes & 11.1 & \multirow[t]{7}{*}{ Easy implementation } & \multirow{7}{*}{$\begin{array}{l}\text { Huge cases required } \\
\text { for proper training }\end{array}$} \\
\hline & 101 & DWT & 3 & PV & Yes & 2.55 & & \\
\hline & 102 & DWT & 4 & Wind & No & 1.01 & & \\
\hline PNN & 104 & DWT & 6 & Not specified & Yes & 11 & & \\
\hline MPNN & 108 & ST & 11 & $\begin{array}{l}\text { PV, fuel cell } \\
\text { and wind }\end{array}$ & Yes & 3.6 & & \\
\hline ENN & 109 & - & 12 & PV & No & 1.6 & & \\
\hline BPNN & 110 & WPT & 13 & PV & No & 1.43 & & \\
\hline \multirow[t]{2}{*}{ SVM } & 108 & ST & 3 & $\begin{array}{l}\text { PV, fuel cell } \\
\text { and wind }\end{array}$ & Yes & 2.33 & \multirow[t]{2}{*}{$\begin{array}{l}\text { Minimized } \\
\text { training error }\end{array}$} & \multirow[t]{2}{*}{$\begin{array}{l}\text { Choice of proper hyper } \\
\text { parameters is cumbersome }\end{array}$} \\
\hline & 73 & $\begin{array}{l}\mathrm{ST} / \mathrm{HST} / \\
\mathrm{TT} / \mathrm{MM}\end{array}$ & 4 & PV and wind & Yes & $\begin{array}{l}4.125 / \\
2.775 / \\
1.725 / \\
1.3\end{array}$ & & \\
\hline \multirow[t]{3}{*}{ ANFIS } & 114 & DWT & 3 & Not specified & No & 0 & \multirow{3}{*}{$\begin{array}{l}\text { No requirement of } \\
\text { mathematical models }\end{array}$} & \multirow{3}{*}{$\begin{array}{l}\text { Both the knowledge of } \\
\text { ANN and Fuzzy is required }\end{array}$} \\
\hline & 115 & - & 4 & DFIG & Yes & 0 & & \\
\hline & 117 & DWT & 6 & $\begin{array}{l}\text { Diesel, wind and } \\
\text { Ni-Cd battery }\end{array}$ & Yes & 0 & & \\
\hline
\end{tabular}


Table 5 Comparison of IDMs

\begin{tabular}{|c|c|c|c|c|c|c|c|}
\hline IDM & Basic principle & NDZ & $\begin{array}{l}\text { Run on } \\
\text { time }\end{array}$ & $\begin{array}{l}\text { Nuisance tripping } \\
\text { percentage }\end{array}$ & $\begin{array}{l}\text { Applicability in } \\
\text { multiple DG system }\end{array}$ & $\begin{array}{l}\text { Implementation } \\
\text { cost }\end{array}$ & $\begin{array}{l}\text { Effect on } \\
\text { microgrid }\end{array}$ \\
\hline Active & $\begin{array}{l}\text { Injecting disturbance and } \\
\text { analyzing the impacts }\end{array}$ & Small & Short & Low & Not preferred & Low & $\begin{array}{l}\text { Highly degrades } \\
\text { the power quality }\end{array}$ \\
\hline Passive & $\begin{array}{l}\text { Monitoring system } \\
\text { parameters }\end{array}$ & Large & $\begin{array}{l}\text { Very } \\
\text { Short }\end{array}$ & High & Highly preferred & Low & None \\
\hline Hybrid & $\begin{array}{l}\text { Combination of active } \\
\text { and passive }\end{array}$ & Very small & Short & Low & Not preferred & Low & $\begin{array}{l}\text { Degrades the } \\
\text { power quality }\end{array}$ \\
\hline Local & $\begin{array}{l}\text { Communication } \\
\text { between DG }\end{array}$ & Zero & High & Negligible & Preferred & Extremely High & None \\
\hline Signal processing & $\begin{array}{l}\text { Extraction of features by } \\
\text { signal processing tools }\end{array}$ & Negligible & Short & Low & Preferred & Low & None \\
\hline Classifier & $\begin{array}{l}\text { Classification based } \\
\text { on input features }\end{array}$ & Negligible & Short & Very low & Preferred & Low & None \\
\hline
\end{tabular}

compared on a single platform. Therefore, the efficacy of such methods varies with test beds.

\section{Future trends}

In light of the synopsis of the IDMS discussed hitherto, various new issues have surfaced that should be tended to by resulting research endeavors. This segment briefly examines the conceivable ranges of future research.

- Though the concept of sequence components is employed for ID, the angle difference between them is not considered till date. There is a possibility of research scope of this concept.

- Smart grid components like smart meters, phasor measurement unit, etc. can be also employed for ID. The advantage of such method will be nonrequirement of any additional hardware or may be even software unit for ID. This will drastically bring down the implementation time and cost making it practically and economical viable.

- Advanced digital signal processing techniques like Discrete Fractional Fourier Transform (DFrFT) combined with learning algorithm may prove to be a potential tool for islanding detection.

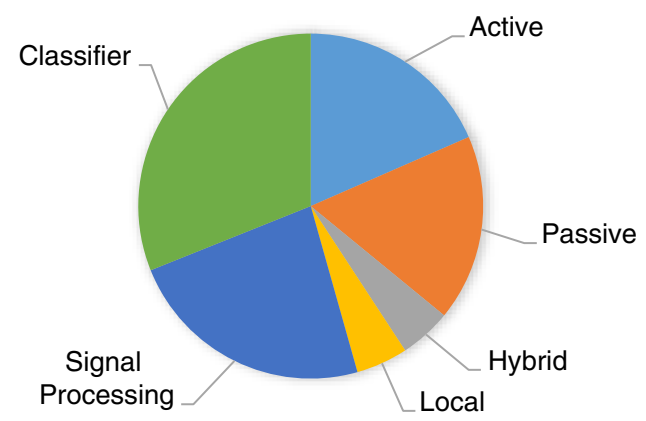

Fig. 17 Percentage of research papers for different IDM
- The IDMs can be upgraded to "smart islanding" where it will detect and accomplish islanding intelligently by employing schemes in the islanded area such as load shedding. This will prevent complete black out in the islanded area rendering the critical loads to be active.

\section{Nomenclature}

$\mathrm{P}_{\text {LOAD }}$ load active power.

$\mathrm{Q}_{\text {LOAD }}$ load reactive power.

$P_{\text {DG }}$ DG active power.

$Q_{D G}$ DG reactive power.

R load resistance $(\Omega)$.

$\mathrm{Q}_{\mathrm{f}}$ load quality factor.

$\mathrm{f}$ main grid frequency $(\mathrm{Hz})$.

$\mathrm{L}$ load inductance $(\mathrm{H})$.

C load capacitance (F).

$\mathrm{C}_{\text {norm }}$ normalized capacitance.

$\mathrm{w}_{\mathrm{o}}$ resonant angular frequency.

$\mathrm{C}_{\text {res }} \mathrm{C}$ resonating with $\mathrm{L}$ at $\mathrm{f}(\mathrm{F})$.

$\mathrm{V}_{\text {max }}$ maximum permissible voltage.

$\mathrm{V}_{\text {min }}$ minimum permissible voltage.

$f_{\max }$ maximum permissible frequency.

$f_{\text {min }}$ minimum permissible frequency.

$\mathrm{V}$ rated voltage.

$\Delta \mathrm{Q}$ reactive power mismatch.

$\Delta \mathrm{P}$ active power mismatch.

$\mathrm{T}_{\mathrm{rt}}$ run on time.

$\mathrm{T}_{\mathrm{mcb}}$ mechanical time of islanding.

$\mathrm{T}_{\text {com }}$ computational time of islanding.

$\mathrm{P}_{\text {nui }}$ nuisance tripping percentage.

$I_{\text {nui }}$ number of nuisance tripping instants.

$\mathrm{I}_{\text {isl }}$ number of correct islanding instants.

$\mathrm{V}^{\prime}$ PCC voltage after islanding.

$\omega^{\prime}$ PCC angular frequency after islanding.

$\alpha$ threshold value.

$\mathrm{df} / \mathrm{dt}$ rate of change of frequency.

$\mathrm{H}$ moment of inertia of DG.

$G$ rated generation capacity of DG. 
$\mathrm{dp} / \mathrm{dt}$ rate of change of power output.

n sampling instant.

tx sampling window length.

cf chopping fraction.

$\mathrm{t}_{\mathrm{z}}$ dead time.

$\mathrm{T}_{\mathrm{vgrid}}$ time period of $\mathrm{V}$.

$\mathrm{cf}_{\mathrm{o}} \mathrm{cf}$ in absence of any frequency error.

$\mathrm{K}$ controller gain.

$f_{\mathrm{PCC}}$ PCC frequency.

VUB voltage unbalance.

$\mathrm{V}_{+}$Sq positive sequence voltage.

$\mathrm{V}_{-\mathrm{Sq}}$ negative sequence voltage.

$\mathrm{T}\left(\mathrm{T}_{\mathrm{av}}, \mathrm{T}_{\mathrm{v}}\right)$ covariance value.

$\mathrm{T}_{\mathrm{av}}$ ' mean of previous four periods of voltage.

$\mathrm{U}_{\mathrm{av}}$ ' average of $\mathrm{T}_{\mathrm{av}}$.

$\mathrm{T}_{\mathrm{v}}$ voltage periods.

$\mathrm{U}_{\mathrm{v}}$ mean of $\mathrm{T}_{\mathrm{av}}$.

$i_{d}$ reactive power shift or $\mathrm{d}$-axis current shift.

$\mathrm{k}_{\mathrm{d}}$ any positive value.

a scaling factor.

b shifting or translational factor.

$\mathrm{a}, \mathrm{b}(\mathrm{t})$ continuous wavelet mother function.

$\mathrm{C}(\mathrm{a}, \mathrm{b})$ continuous wavelet transform.

$\mathrm{a}_{0}$ dyadic dilation factor.

$\mathrm{b}_{0}$ dyadic translation factor.

q.r $(t)$ discrete wavelet mother function.

$\mathrm{D}(\mathrm{q}, \mathrm{r})$ discrete wavelet transform.

$\mathrm{Q}$ integer.

$r$ integer.

$\mathrm{S}(\mathrm{\tau}, \mathrm{f})$ Stockwell transform.

$\mathrm{u}(\mathrm{t})$ analyzed signal.

fr frequency.

$\mathrm{t}$ time.

$\tau$ position parameter of window function on $t$ axis.

$\mathrm{d}$ time frequency resolution control parameter.

$\mathrm{w}$ window function.

$\mathrm{TT}(\mathrm{t}, \mathrm{\tau})$ time time transform.

$\varsigma_{n n}$ transfer function.

nn neuron.

$\mathrm{y}_{\mathrm{nn}} \mathrm{nn}$ output.

$\mathrm{x}_{\mathrm{j}} \mathrm{j}^{\text {th }}$ input of nn.

$\mathrm{w}_{\mathrm{nnj}}$ connection weight between $\mathrm{nn}$ and $\mathrm{j}$.

$b_{n n}$ bias or threshold of $n n$.

\section{Authors' contributions}

SD has carried out study of islanding along with its technical issues, test systems and standards, various detection methods and developed the criterions for their comparison. PKS, MJBR and DKM has been the technical adviser of the complete work, has supported in interpreting the basic methods and trends for islanding detection and helped in drafting the manuscript. All authors read and approved the final manuscript.

\section{Competing interests}

The authors declare that they have no competing interests.

\section{Author details}

'Department of Electrical Engineering, Indian Institute of Technology (Indian School of Mines), Dhanbad, Jharkhand, India. ${ }^{2}$ Department of Electrical and Electronics Engineering, National Institute of Technology, Tiruchirappalli, Tamilnadu, India. ${ }^{3}$ Department of Electrical and Electronics Engineering, Birla Institute of Technology, Mesra, Ranchi, Jharkhand, India.

Received: 18 September 2017 Accepted: 11 December 2017

Published online: 19 January 2018

\section{References}

1. El-Khattam, W., \& Salama, M. M. (2004). Distributed generation technologies, definitions and benefits. Electr Power Syst Res, 71(2), 119-128.

2. Eltawil, M. A., \& Zhao, Z. (2010). Grid-connected photovoltaic power systems: Technical and potential problems-A review. Renew Sust Energ Rev, 14(1), 112-129.

3. Cossent, R., Gómez, T., \& Frías, P. (2009). Towards a future with large penetration of distributed generation: Is the current regulation of electricity distribution ready? Regulatory recommendations under a European perspective. Energy Policy, 37(3), 1145-1155.

4. Walling, R. A., \& Miller, N. W. (2002). Distributed generation islandingimplications on power system dynamic performance, In power engineering society summer meeting, 2002 IEEE (Vol. 1, pp. 92-96). Piscataway: IEEE.

5. De Mango, F., Liserre, M., Dell'Aquila, A., \& Pigazo, A. (2006). Overview of antiislanding algorithms for PV systems, Part I: Passive methods. In power electronics and motion control conference, 2006. EPE-PEMC 2006. 12th international (pp. 1878-1883). Piscataway: IEEE.

6. Basso, T. S., \& DeBlasio, R. (2004). IEEE 1547 series of standards: Interconnection issues. IEEE Trans Power Electron, 19(5), 1159-1162.

7. Wang, C., \& Li, P. (2010). Development and challenges of distributed generation, the micro-grid and smart distribution system. Automation of Electric Power Systems, 2, 004.

8. Katiraei, F., Iravani, M. R., \& Lehn, P. W. (2005). Micro-grid autonomous operation during and subsequent to islanding process. IEEE Transactions on power delivery, 20(1), 248-257.

9. Vachtsevanos, G. J., \& Kang, H. (1989). Simulation studies of islanded behavior of grid-connected photovoltaic systems. IEEE Transactions on Energy Conversion, 4(2), 177-183.

10. Balaguer, I. J., Lei, Q., Yang, S., Supatti, U., \& Peng, F. Z. (2011). Control for grid-connected and intentional islanding operations of distributed power generation. IEEE Trans Ind Electron, 58(1), 147-157.

11. Kunte, R. S., \& Gao, W. (2008). Comparison and review of islanding detection techniques for distributed energy resources, In power symposium, 2008. NAPS'08. 40th north American (pp. 1-8). Piscataway: IEEE.

12. Shahmohammadi, A., \& Ameli, M. T. (2014). Proper sizing and placement of distributed power generation aids the intentional islanding process. Electr Power Syst Res, 106, 73-85.

13. Zeineldin, H. H., Bhattacharya, K., El-Saadany, E. F., \& Salama, M. M. A. (2006). Impact of intentional islanding of distributed generation on electricity market prices. IEE Proceedings-Generation, Transmission and Distribution, 153(2) , 147-154.

14. Ahmad, K. N. E. K., Selvaraj, J., \& Rahim, N. A. (2013). A review of the islanding detection methods in grid-connected PV inverters. Renew Sust Energ Rev, 21, 756-766.

15. Yu, B., Matsui, M., \& Yu, G. (2010). A review of current anti-islanding methods for photovoltaic power system. Sol Energy, 84(5), 745-754.

16. Zhang, Y., Sun, H., \& Lopes, L. A. (2007). 1 an islanding detection enhancer for a system with multiple photovoltaic inverters.

17. Ropp, M. E., Begovic, M., Rohatgi, A., Kern, G. A., Bonn, R. H., \& Gonzalez, S. (2000). Determining the relative effectiveness of islanding detection methods using phase criteria and nondetection zones. IEEE transactions on energy conversion, 15(3), 290-296.

18. Sun, H. (2005). Performance assessment of islanding detection methods using the concept of non-detection zones. Montreal: Doctoral dissertation, Concordia University.

19. Ye, Z., Kolwalkar, A., Zhang, Y., Du, P., \& Walling, R. (2004). Evaluation of antiislanding schemes based on nondetection zone concept. IEEE Trans Power Electron, 19(5), 1171-1176.

20. Vieira, J. C., Salles, D., \& Freitas, W. (2011). Power imbalance application region method for distributed synchronous generator anti-islanding protection design and evaluation. Electr Power Syst Res, 81(10), 1952-1960. 
21. PVPS, I. (2002). Evaluation of islanding detection methods for photovoltaic utility-interactive power systems. Report IEA PVPS T5-09.

22. Singam, B., \& Hui, L. Y. (2006). Assessing SMS and PJD schemes of antiislanding with varying quality factor, In power and energy conference, 2006. PECon'06. IEEE international (pp. 196-201). Piscataway: IEEE.

23. Hung, G. K., Chang, C. C., \& Chen, C. L. (2003). Automatic phase-shift method for islanding detection of grid-connected photovoltaic inverters. IEEE Transactions on energy conversion, 18(1), 169-173.

24. Merino, J., Mendoza-Araya, P., Venkataramanan, G., \& Baysal, M. (2015). Islanding detection in microgrids using harmonic signatures. IEEE Transactions on Power Delivery, 30(5), 2102-2109.

25. Kim, I. S. (2012). Islanding detection technique using grid-harmonic parameters in the photovoltaic system. Energy Procedia, 14, 137-141.

26. Redfern, M. A., Usta, O., \& Fielding, G. (1993). Protection against loss of utility grid supply for a dispersed storage and generation unit. IEEE Transactions on Power Delivery, 8(3), 948-954.

27. Freitas, W., Xu, W., Affonso, C. M., \& Huang, Z. (2005). Comparative analysis between ROCOF and vector surge relays for distributed generation applications. IEEE Transactions on power delivery, 20(2), 1315-1324.

28. Liu, N., Aljankawey, A., Diduch, C., Chang, L., \& Su, J. (2015). Passive islanding detection approach based on tracking the frequency-dependent impedance change. IEEE Transactions on Power Delivery, 30(6), 2570-2580.

29. O'kane, P., \& Fox, B. (1997). Loss of mains detection for embedded generation by system impedance monitoring.

30. Samet, H., Hashemi, F., \& Ghanbari, T. (2015). Islanding detection method for inverter-based distributed generation with negligible non-detection zone using energy of rate of change of voltage phase angle. IET Generation, Transmission \& Distribution, 9(15), 2337-2350.

31. Liu, N., Diduch, C., Chang, L., \& Su, J. (2015). A reference impedance-based passive islanding detection method for inverter-based distributed generation system. IEEE Journal of Emerging and Selected Topics in Power Electronics, 3(4), 1205-1217.

32. Marchesan, G., Muraro, M. R., Cardoso, G., Mariotto, L., \& De Morais, A. P. (2016). Passive method for distributed-Generation Island detection based on oscillation frequency. IEEE Transactions on Power Delivery, 31(1), 138-146.

33. Sareen, K., Bhalja, B. R., \& Maheshwari, R. P. (2016). Universal islanding detection technique based on rate of change of sequence components of currents for distributed generations. IET Renewable Power Generation, 10(2), 228-237.

34. Raza, S., Mokhlis, H., Arof, H., Laghari, J. A., \& Mohamad, H. (2016). A sensitivity analysis of different power system parameters on islanding detection. IEEE Transactions on Sustainable Energy, 7(2), 461-470.

35. Reigosa, D., Briz, F., Blanco, C., \& Guerrero, J. M. (2017). Passive islanding detection using inverter nonlinear effects. IEEE transactions on power electronics.

36. Lopes, L. A., \& Sun, H. (2006). Performance assessment of active frequency drifting islanding detection methods. IEEE Transactions on Energy Conversion, 27(1), 171-180.

37. Liu, F., Kang, Y., Zhang, Y., Duan, S., \& Lin, X. (2010). Improved SMS islanding detection method for grid-connected converters. IET renewable power generation, 4(1), 36-42.

38. Ropp, M. E., Begovic, M., \& Rohatgi, A. (1999). Prevention of islanding in grid-connected photovoltaic systems. Prog Photovolt Res Appl, 7(1), 39-59.

39. Wen, B., Boroyevich, D., Burgos, R., Shen, Z., \& Mattavelli, P. (2016). Impedance-based analysis of active frequency drift islanding detection for grid-tied inverter system. IEEE Trans Ind Appl, 52(1), 332-341.

40. Ropp, M. E., Begovic, M., \& Rohatgi, A. (1999). Analysis and performance assessment of the active frequency drift method of islanding prevention. IEEE Transactions on Energy conversion, 14(3), 810-816.

41. Zeineldin, H. H., \& Conti, S. (2011). Sandia frequency shift parameter selection for multi-inverter systems to eliminate non-detection zone. IET Renewable Power Generation, 5(2), 175-183.

42. Wang, X., Freitas, W., Xu, W., \& Dinavahi, V. (2007). Impact of DG interface controls on the sandia frequency shift antiislanding method. IEEE Transactions on Energy Conversion, 22(3), 792-794.

43. Trujillo, C. L., Velasco, D., Figueres, E., \& Garcerá, G. (2010). Analysis of active islanding detection methods for grid-connected microinverters for renewable energy processing. Appl Energy, 87(11), 3591-3605.

44. El-Moubarak, M., Hassan, M., \& Faza, A. (2015). Performance of three islanding detection methods for grid-tied multi-inverters, In environment and electrical engineering (EEEIC), 2015 IEEE 15th international conference on (pp. 19992004). Piscataway: IEEE.
45. Karimi, H., Yazdani, A., \& Iravani, R. (2008). Negative-sequence current injection for fast islanding detection of a distributed resource unit. IEEE Trans Power Electron, 23(1), 298-307.

46. Gupta, P., Bhatia, R. S., \& Jain, D. K. (2015). Average absolute frequency deviation value based active islanding detection technique. IEEE Transactions on Smart Grid, 6(1), 26-35.

47. Reigosa, D. D., Briz, F., Charro, C. B., \& Guerrero, J. M. (2015). Islanding detection in three-phase and single-phase systems using pulsating highfrequency signal injection. IEEE Trans Power Electron, 30(12), 6672-6683.

48. Al Hosani, M., Qu, Z., \& Zeineldin, H. H. (2015). A transient stiffness measure for islanding detection of multi-DG systems. IEEE Transactions on Power Delivery, 30(2), 986-995.

49. Hamzeh, M., Rashidirad, N., Sheshyekani, K., \& Afjei, E. (2016). A new islanding detection scheme for multiple inverter-based DG systems. IEEE Transactions on Energy Conversion, 31(3), 1002-1011.

50. Pourbabak, H., \& Kazemi, A. (2016). Islanding detection method based on a new approach to voltage phase angle of constant power inverters. IET Generation, Transmission \& Distribution, 10(5), 1190-1198.

51. Sun, Q., Guerrero, J. M., Jing, T., Vasquez, J. C., \& Yang, R. (2017). An islanding detection method by using frequency positive feedback based on FLL for single-phase microgrid. IEEE Transactions on Smart Grid, 8(4), 1821-1830.

52. Menon, V., \& Nehrir, M. H. (2007). A hybrid islanding detection technique using voltage unbalance and frequency set point. IEEE Trans Power Syst, 22(1), 442-448.

53. Mahat, P., Chen, Z., \& Bak-Jensen, B. (2008). Review of islanding detection methods for distributed generation, In electric utility deregulation and restructuring and power technologies, 2008. DRPT 2008. Third international conference on (pp. 2743-2748). Piscataway: IEEE.

54. Yin, J., Chang, L., \& Diduch, C. (2006). A new hybrid anti-islanding algorithm in grid connected three-phase inverter system, In 2006 IEEE power electronics specialists conference (pp. 1-7).

55. Vahedi, H., Noroozian, R., Jalilvand, A., \& Gharehpetian, G. B. (2010). Hybrid SFS and Qf islanding detection method for inverter-based DG, In power and energy (PECOn), 2010 IEEE international conference on (pp. 672-676). Piscataway: IEEE.

56. Mahat, P., Chen, Z., \& Bak-Jensen, B. (2009). A hybrid islanding detection technique using average rate of voltage change and real power shift. IEEE Transactions on Power delivery, 24(2), 764-771.

57. Etxegarai, A., Eguía, P., \& Zamora, I. (2011). Analysis of remote islanding detection methods for distributed resources. In Int. conf. Renew. Energies power quality.

58. Walling, R. A. (2011). Application of direct transfer trip for prevention of DG islanding, In power and energy society general meeting, 2011 IEEE (pp. 1-3). Piscataway: IEEE.

59. Ropp, M., Joshi, D., Reedy, R., Davis, K., Click, D., \& Shaffer, A. (2011). New results for power line carrier-based islanding detection and an updated strengths and weaknesses discussion, In photovoltaic specialists conference (PVSC), 2011 37th IEEE (pp. 002584-002587). Piscataway: IEEE.

60. Perlenfein, S., Ropp, M., Neely, J., Gonzalez, S., \& Rashkin, L. (2015). Subharmonic power line carrier (PLC) based island detection, In applied power electronics conference and exposition (APEC), 2015 IEEE (pp. 2230-2236). Piscataway: IEEE.

61. Chen, S. (2005). Feature selection for identification and classification of power quality disturbances, In power engineering society general meeting, 2005. IEEE (pp. 2301-2306). Piscataway: IEEE.

62. Daubechies, I. (1990). The wavelet transform, time-frequency localization and signal analysis. IEEE Trans Inf Theory, 36(5), 961-1005.

63. Zhu, Y., Yang, Q., Wu, J., Zheng, D., \& Tian, Y. (2008). A novel islanding detection method of distributed generator based on wavelet transform, In electrical machines and systems, 2008. ICEMS 2008. International conference on (pp. 2686-2688). Piscataway: IEEE.

64. Mallat, S. G. (1989). A theory for multiresolution signal decomposition: The wavelet representation. IEEE Trans Pattern Anal Mach Intell, 11(7), 674-693.

65. Pigazo, A., Liserre, M., Mastromauro, R. A., Moreno, V. M., \& Dell'Aquila, A. (2009). Wavelet-based islanding detection in grid-connected PV systems. IEEE Trans Ind Electron, 56(11), 4445-4455.

66. Hsieh, C. T., Lin, J. M., \& Huang, S. J. (2008). Enhancement of islandingdetection of distributed generation systems via wavelet transform-based approaches. Int J Electr Power Energy Syst, 30(10), 575-580.

67. Hanif, M., Dwivedi, U. D., Basu, M., \& Gaughan, K. (2010). Wavelet based islanding detection of DC-AC inverter interfaced $D G$ systems, In universities power engineering conference (UPEC), 2010 45th international (pp. 1-5). Piscataway: IEEE. 
68. Hanif, M., Basu, M., \& Gaughan, K. (2012). Development of EN50438 compliant wavelet-based islanding detection technique for three-phase static distributed generation systems. IET renewable power generation, 6(4), 289-301.

69. Karegar, H. K., \& Sobhani, B. (2012). Wavelet transform method for islanding detection of wind turbines. Renew Energy, 38(1), 94-106.

70. Ning, J., \& Wang, C. (2012). Feature extraction for islanding detection using wavelet transform-based multi-resolution analysis, In power and energy society general meeting, 2012 IEEE (pp. 1-6). Piscataway: IEEE.

71. Mohanty, S. R., Kishor, N., Ray, P. K., \& Catalão, J. P. (2012). Islanding detection in a distributed generation based hybrid system using intelligent pattern recognition techniques, In innovative smart grid technologies (ISGT Europe), 2012 3rd IEEE PES international conference and exhibition on (pp. 1-5). Piscataway: IEEE.

72. Samui, A., \& Samantaray, S. R. (2013). Wavelet singular entropy-based islanding detection in distributed generation. IEEE transactions on power delivery, 28(1), 411-418

73. Mohanty, S. R., Kishor, N., Ray, P. K., \& Catalo, J. P. (2015). Comparative study of advanced signal processing techniques for islanding detection in a hybrid distributed generation system. IEEE Transactions on sustainable Energy, 6(1), 122-131

74. Morsi, W. G., Diduch, C. P., \& Chang, L. (2010). A new islanding detection approach using wavelet packet transform for wind-based distributed generation, In power electronics for distributed generation systems (PEDG), 2010 2nd IEEE international symposium on (pp. 495-500). Piscataway: IEEE.

75. Stockwell, R. G., Mansinha, L., \& Lowe, R. P. (1996). Localisation of the complex spectrum: The S transform. J Assoc Explor Geophys, 17(3), 99-114.

76. Dehghani, M. J. (2009). Comparison of S-transform and wavelet transform in power quality analysis. World Acad Sci Eng Technol, 50(4), 395-398.

77. Ray, P. K., Mohanty, S. R., \& Kishor, N. (2011). Disturbance detection in gridconnected distributed generation system using wavelet and S-transform. Electr Power Syst Res, 81(3), 805-819.

78. Samantaray, S. R., Samui, A., \& Babu, B. C. (2010). S-transform based cumulative sum detector (CUSUM) for islanding detection in distributed generations, In power electronics, drives and energy systems (PEDES) \& 2010 power India, 2010 joint international conference on (pp. 1-6). Piscataway: IEEE.

79. Ashrafian, A., Rostami, M., \& Gharehpetian, G. B. (2012). Hyperbolic Stransform-based method for classification of external faults, incipient faults, inrush currents and internal faults in power transformers. IET generation, transmission \& distribution, 6(10), 940-950.

80. Simon, C., Schimmel, M., \& Dañobeitia, J. J. (2008). On the TT-transform and its diagonal elements. IEEE Trans Signal Process, 56(11), 5709-5713.

81. Khamis, A., Shareef, H., \& Wanik, M. Z. C. (2012). Pattern recognition of islanding detection using tt-transform. Journal of Asian Scientific Research, 2(11), 607.

82. Huang, N. E., Shen, Z., Long, S. R., Wu, M. C., Shih, H. H., Zheng, Q., ... \& Liu, H. H. (1998). The empirical mode decomposition and the Hilbert spectrum for nonlinear and non-stationary time series analysis. In proceedings of the Royal Society of London a: Mathematical, physical and engineering sciences (Vol. 454, No. 1971, pp. 903-995). London: The Royal Society.

83. Donnelly, D. (2006). The fast Fourier and Hilbert-Huang transforms: A comparison, In computational engineering in systems applications, IMACS multiconference on (Vol. 1, pp. 84-88). Piscataway: IEEE.

84. Niaki, A. M., \& Afsharnia, S. (2014). A new passive islanding detection method and its performance evaluation for multi-DG systems. Electr Power Syst Res, 110, 180-187.

85. Maragos, P., \& Schafer, R. (1987). Morphological filters-part I: Their settheoretic analysis and relations to linear shift-invariant filters. IEEE Trans Acoust Speech Signal Process, 35(8), 1153-1169.

86. Safavian, S. R., \& Landgrebe, D. (1991). A survey of decision tree classifier methodology. IEEE transactions on systems, man, and cybernetics, 21(3), 660-674.

87. El-Arroudi, K., Joos, G., Kamwa, I., \& McGillis, D. T. (2007). Intelligent-based approach to islanding detection in distributed generation. IEEE transactions on power delivery, 22(2), 828-835.

88. Madani, S. S., Abbaspour, A., Beiraghi, M., Dehkordi, P. Z., \& Ranjbar, A. M. (2012). Islanding detection for PV and DFIG using decision tree and AdaBoost algorithm, In innovative smart grid technologies (ISGT Europe), 2012 3rd IEEE PES international conference and exhibition on (pp. 1-8). Piscataway: IEEE.

89. Lidula, N. W. A., \& Rajapakse, A. D. (2010). A pattern recognition approach for detecting power islands using transient signals-part I: Design and implementation. IEEE Transactions on Power Delivery, 25(4), 3070-3077
90. Lidula, N. W. A., \& Rajapakse, A. D. (2012). A pattern-recognition approach for detecting power islands using transient signals-part II: Performance evaluation. IEEE Transactions on Power Delivery, 27(3), 1071-1080.

91. Heidari, M., Seifossadat, G., \& Razaz, M. (2013). Application of decision tree and discrete wavelet transform for an optimized intelligent-based islanding detection method in distributed systems with distributed generations. Renew Sust Energ Rev, 27, 525-532.

92. Vatani, M., Amraee, T., Ranjbar, A. M., \& Mozafari, B. (2015). Relay logic for islanding detection in active distribution systems. IET Generation, Transmission \& Distribution, 9(12), 1254-1263.

93. Zhou, B., Cao, C., Li, C., Cao, Y., Chen, C., Li, Y., \& Zeng, L. (2015). Hybrid islanding detection method based on decision tree and positive feedback for distributed generations. IET Generation, Transmission \& Distribution, 9(14), 1819-1825.

94. Wang, L. X., \& Mendel, J. M. (1992). Generating fuzzy rules by learning from examples. IEEE Transactions on systems, man, and cybernetics, 22(6), 14141427.

95. Rosolowski, E., Burek, A., \& Jedut, L. (2007). A new method for islanding detection in distributed generation. Poljska: Wroclaw University of Technology.

96. Samantaray, S. R., El-Arroudi, K., Joos, G., \& Kamwa, I. (2010). A fuzzy rulebased approach for islanding detection in distributed generation. IEEE Transactions on Power Delivery, 25(3), 1427-1433.

97. Shi, L., \& Wu, F. (2013). An islanding detection algorithm based on fuzzy adaptive phase drift control, In information and automation (ICIA), 2013 IEEE international conference on (pp. 225-229). Piscataway: IEEE.

98. Vahedi, H., \& Karrari, M. (2013). Adaptive fuzzy sandia frequency-shift method for islanding protection of inverter-based distributed generation. IEEE Transactions on Power Delivery, 28(1), 84-92.

99. Yao, X. (1999). Evolving artificial neural networks. Proc IEEE, 87(9), 1423-1447.

100. Ghazi, R., \& Lotfi, N. (2010). A new hybrid intelligent based approach to islanding detection in distributed generation, In universities power engineering conference (UPEC), 2010 45th international (pp. 1-5). Piscataway: IEEE.

101. Fayyad, Y., \& Osman, A. (2010). Neuro-wavelet based islanding detection technique, In electric power and energy conference (EPEC), 2010 IEEE (pp. 1-6). Piscataway: IEEE.

102. ElNozahy, M. S., El-Saadany, E. F., \& Salama, M. M. (2011). A robust waveletANN based technique for islanding detection, In power and energy society general meeting, 2011 IEEE (pp. 1-8). Piscataway: IEEE.

103. Abd-Elkader, A. G., Allam, D. F., \& Tageldin, E. (2014). Islanding detection method for DFIG wind turbines using artificial neural networks. Int J Electr Power Energy Syst, 62, 335-343.

104. Lidula, N. W. A., \& Rajapakse, A. D. (2009). Fast and reliable detection of power islands using transient signals, In industrial and information systems (ICIIS), 2009 international conference on (pp. 493-498). Piscataway: IEEE.

105. Moeini, A., Darabi, A., \& Karimi, M. (2010). Clustering governor signal of distributed generation for islanding detection, In computational Technologies in Electrical and Electronics Engineering (SIBIRCON), 2010 IEEE region 8 international conference on (pp. 493-498). Piscataway: IEEE.

106. Moeini, A., Darabi, A., Rafiei, S. M. R., \& Karimi, M. (2011). Intelligent islanding detection of a synchronous distributed generation using governor signal clustering. Electr Power Syst Res, 81(2), 608-616.

107. Chao, K. H., Chiu, C. L., Li, C. J., \& Chang, Y. C. (2011). A novel neural network with simple learning algorithm for islanding phenomenon detection of photovoltaic systems. Expert Syst Appl, 38(10), 12107-12115.

108. Mohanty, S. R., Ray, P. K., Kishor, N., \& Panigrahi, B. K. (2013). Classification of disturbances in hybrid DG system using modular PNN and SVM. Int J Electr Power Energy Syst, 44(1), 764-777.

109. Wang, M. H., Huang, M. L., \& Liou, K. J. (2015). Islanding detection method for grid connected photovoltaic systems. IET Renewable Power Generation, 9(6), 700-709

110. Do, H. T., Zhang, X., Nguyen, N. V., Li, S. S., \& Chu, T. T. T. (2016). Passiveislanding detection method using the wavelet packet transform in grid-connected photovoltaic systems. IEEE Trans Power Electron, 31(10), 6955-6967.

111. Janik, P., \& Lobos, T. (2006). Automated classification of power-quality disturbances using SVM and RBF networks. IEEE Transactions on Power Delivery, 21(3), 1663-1669.

112. Jang, J. S. (1993). ANFIS: Adaptive-network-based fuzzy inference system. IEEE transactions on systems, man, and cybernetics, 23(3), 665-685. 
113. Hashemi, F., Ghadimi, N., \& Sobhani, B. (2013). Islanding detection for inverter-based DG coupled with using an adaptive neuro-fuzzy inference system. Int J Electr Power Energy Syst, 45(1), 443-455.

114. Shayeghi, H., \& Sobhani, B. (2014). Zero NDZ assessment for anti-islanding protection using wavelet analysis and neuro-fuzzy system in inverter based distributed generation. Energy Convers Manag, 79, 616-625.

115. Bitaraf, H., Sheikholeslamzadeh, M., Ranjbar, A. M., \& Mozafari, B. (2012). Neuro-fuzzy islanding detection in distributed generation, In innovative smart grid technologies-Asia (ISGT Asia), 2012 IEEE (pp. 1-5). Piscataway: IEEE.

116. Lin, F. J., Huang, Y. S., Tan, K. H., Chiu, J. H., \& Chang, Y. R. (2013). Active islanding detection method using $d$-axis disturbance signal injection with intelligent control. IET Generation, Transmission \& Distribution, 7(5), 537-550.

117. Kermany, S. D., Joorabian, M., Deilami, S., \& Masoum, M. A. (2017). Hybrid islanding detection in microgrid with multiple connection points to smart grids using fuzzy-neural network. IEEE Trans Power Syst, 32(4), 2640-2651.

\section{Submit your manuscript to a SpringerOpen ${ }^{\circ}$ journal and benefit from:}

- Convenient online submission

- Rigorous peer review

- Open access: articles freely available online

- High visibility within the field

- Retaining the copyright to your article

Submit your next manuscript at $\boldsymbol{s p r i n g e r o p e n . c o m ~}$ 